Article

\title{
Green Supply Chain Collaboration for Fashionable Consumer Electronics Products under Third-Party Power Intervention-A Resource Dependence Perspective
}

\author{
Jiuh-Biing Sheu \\ Department of Business Administration, National Taiwan University, No.1, Sec. 4, Roosevelt Road, \\ Taipei 10617, Taiwan; E-Mail: jbsheu@ntu.edu.tw; Tel.: +886-2-3366-1069; Fax: +886-2-2362-5379
}

Received: 1 April 2014; in revised form: 26 April 2014 / Accepted: 8 May 2014 /

Published: 13 May 2014

\begin{abstract}
Under third-party power intervention (TPPI), which increases uncertainty in task environments, complex channel power interplays and restructuring are indispensable among green supply chain members as they move toward sustainable collaborative relationships for increased viability and competitive advantage. From the resource dependence perspective, this work presents a novel conceptual model to investigate the influence of political and social power on channel power restructuring and induced green supply chain collaboration in brander-retailer bidirectional green supply chains of fashionable consumer electronics products (FCEPs). An FCEP refers to the consumer electronics product (e.g., personal computers, mobile phones, computer notebooks, and game consoles) with the features of a well-known brand associated, a short product lifecycle, timely and fashionable design fit for market trends, and quick responsiveness to the variations of market demands. The proposed model is tested empirically using questionnaire data obtained from retailers in the FCEP brander-retailer distribution channels. Analytical results reveal that as an extension of political and social power, TPPI positively affects the reciprocal interdependence of dyadic members and reduces power asymmetry, thereby enhancing the collaborative relationship of dyadic members and leading to improved green supply chain performance. Therein, reciprocal interdependence underlying collaborative relationship is the key to reducing the external environmental uncertainties in the TPPI context.
\end{abstract}

Keywords: power restructuring; resource dependence; collaborative relationships; green supply chain performance; resource dependence theory 


\section{Introduction}

As the concept of extended producer responsibility has emerged around the world, there are plenty of practical cases showing that third-party power intervention (TPPI) by governments and non-profit organizations has significantly influenced supply chain performance as supply chains evolve toward collaborative green supply chains. This argument holds particularly for the global manufacturing industries of fashionable consumer electronics products (FCEPs). In this work, an FCEP refers to the consumer electronics product (e.g., personal computers, mobile phones, computer notebooks, and game consoles) with the features of a well-known brand associated, a short product lifecycle, timely and fashionable design fit for market trends, and quick responsiveness to the variations of market demands. From a supply chain perspective, FCEPs requires agile and sustainable supply chains with the operational features of shortened lead times, faster inventory turnovers, high order fulfillment rates and quick responses to customer demands, integrated with well-established reverse logistics services (e.g., repairing, maintenance, customer returns, and recycling) and networks for sustainable competitive advantage [1-4]. For example, the Waste Electrical and Electronic Equipment (WEEE) directive and Restriction on Hazardous Substances (RoHS) have increased regulatory-compliance costs by 3\%-10\% for branders of consumer electronics products [5]. In the US, 22 states have passed e-waste bills which have caused producers to bear additional responsibility for e-waste collection and recycling, leading producers to seek new partners for solutions in reverse channels [6-8]. Another TPPI example is the guide to green electronics products issued by Greenpeace International which ranks the top 18 global FCEP branders quarterly, based on the manufacturers' policies for toxic chemicals, recycling, and climate change. Accordingly, TPPI-induced expenses and responsibilities have increased not only the producers' burdens, but also their awareness of the need for close collaboration with reverse channel members. Notably, TPPI is likely to engender the awareness of reverse channel members of their importance in green supply chains. Thus, channel power structure and the interdependence of producers and reverse channel members are likely altered in green supply chains.

Nevertheless, several examples from well-known brands (e.g., IBM, Apple, and Hewlett-Packard) have transformed regulatory compliance into a requirement of sustainable competitive advantage. For example, by transforming recycling and compliance into a sustainable business model, IBM now collects and recycles about 20,000 end-of-lease machines weekly, adding several millions of dollars in revenue and less than $2 \%$ of end-of-lease products to landfills [9]. Another case is Apple, which collaborates with its worldwide retail stores to implement elaborately integrated green marketing and recycling programs, where end-customers are strongly encouraged to return Apple products for recycling by providing them with such economic incentives as Apple gift cards. Under close producer-retailer collaboration, the goals of green regulatory compliance and sustainable competitive advantage can be achieved efficiently [10].

Due to the necessity of managing forward and reverse logistics flows of FCEP green supply chains in the TPPI contexts, the role of a retailer, which acts as a producer's partner in a bi-directional FCEP green supply chain composed of a forward distribution channel and reverse channel is drawing increasing attention. According to the concept of product stewardship [11], retailers should act as an interface between producers and consumers when managing the lifecycles of FCEPs. This holds true, 
particularly in the case of individual producer-operated e-waste management systems that are based on the concept of individual producer responsibility. In Japan, for example, FCEP-branders prefer collecting and recycling their own products via contracted retailers so they can control cost, control quality in green manufacturing, and optimize product recyclability by green design [12]. Several European states such as Belgium, France, and Germany rely heavily on retailers for e-waste collection [13].

In the case that a retailer has to jointly bear the additional responsibility of managing reverse logistics flows for repair and recycling in an FCEP green supply chain, issues of producer-retailer interdependence and power imbalance may become increasingly complex. In practice, producer-retailer collaboration in bidirectional distribution operations to collect used FCEPs, e.g., mobile phones and single-use cameras, from end-customers for repair and recycling, have been increasingly adopted by the dyadic members. These collaborative operations are easily found in the producer-retailer distribution channels for FCEPs. A producer and retailer, thus, may no longer be limited to a producer-retailer transaction relationship typically revealed in a one-directional forward supply chain. Rather, so-called reciprocal task interdependence may exist between dyadic channel members $[14,15]$. Furthermore, the political and social power driven by TPPI may push FCEP-producers and retailers to be inextricably linked as the dyadic members conjecture the increase in the interdependence on mutual resources to carry out extended producer responsibility. Numerous practical cases have also indicated that producers that were powerful supply chain members require support from reverse channel partners, including contracted retailers, to comply with take-back directives; otherwise, producers risk violating WEEE directives [16]. Therefore, both FCEP-producers and retailers must resolve issues related to interdependence and power imbalance when moving toward green supply chain collaboration with improved chain performance.

The aforementioned FCEP producer-retailer bidirectional channel collaboration, in reality, stems from the concept of green supply chain management, which claims that functions of forward and reverse supply chains should be integrated efficiently, and chain members should be coordinated to solve joint problems, and achieve joint goals via joint strategic planning and actions [17,18]. Despite remarkable advances made by pioneering green supply chain management research [17,19-24], issues related to the interplays and relational governance as green supply chain members move toward a long-term collaborative green supply chain under TPPI remain challenging [18,25,26]. As argued in Sarkis et al. [18], the interdependency of green supply chain members and their effectiveness determine the success of green supply chain management from a resource dependence perspective; however, they have not yet been satisfactorily addressed in literature. According to Dill [27] and Duncan [28], governments and green organizations can be regarded as a part of "task environments" in green supply chains. By Bourgeois [29], we speculate that the TPPI-oriented political and social power is one of exogenous sources causing environmental heterogeneity and complexity in business operations, contributing to the increased uncertainties of task environments for green supply chain members. From a resource dependence perspective, for those firms (e.g., producers) lacking the resources needed to carry out extended producer responsibility, developing long-term collaborative relationships with other chain members that possess the necessary resources is indispensible to ensure their on-going viability and success under TPPI [30,31]. Nevertheless, the aforementioned power-interaction phenomena between dyadic green supply chain members under TPPI, and its effects 
on green supply chain collaboration and performance are rarely investigated in green supply chain management literature. Founded on resource dependence theory [30], this study investigates direct effects of TPPI-oriented political and social power on channel power restructuring, and its indirect effects on collaborative relationships in, and channel performance of, producer-retailer channel dyads in green supply chains.

Resource dependence theory has been broadly applied to explain how organizations reduce environmental uncertainty by seeking and controlling the resources required to move toward the goal of maximizing organizational power for survival and success [30-32]. Although resource dependence theory assumes that organizations struggle to acquire control over resources that either minimize their dependence on other organizations or maximize the dependence of other organizations on themselves, the corresponding measures are unnecessarily coercive [33,34]. Instead, a growing number of researchers advocate that channel dependence should be built upon harmonic, symbiotic, and collaborative relationships [35-39]. Based on resource dependence theory literature [15,30], we argue that resource dependence theory provides a foundation to rationalize channel power restructuring phenomena, characterized particularly by resource interdependence and power asymmetry, to achieve the collective goals of a green distribution channel under TPPI. For instance, Crook and Combs [15] applied resource dependence theory to describe the relationship between bargaining power and supply chain members' benefits gained via collaboration. Hillman et al. [40] pointed out that uncertainty and dependence on law and social sanctions were noted by Pfeffer and Salancik [30]; however, their effect on organizational performance is often overlooked in resource dependence theory literature. Similar arguments can also be found in the study by Aharoni et al. [41], who claim that governments are one of the most difficult environmental uncertainties to control due to the heterogeneous interests of different agencies and political decision makers. Motivated by the studies by Hillman et al. [40] and Aharoni et al. [41], this work addresses the issue of intervention by governments and green organizations in FCEP green supply chain collaboration. Moreover, we argue that FCEP green supply chain members, such as producers and contracted retailers, should work together to collectively reduce the environmental uncertainties of the larger socio-political system. This is in contrast to the use of either power control over dyadic members or political means to alter the conditions of external environments under TPPI.

Accordingly, from the collaborative perspective of resource dependence theory, this work contributes to green supply chain management by offering managerial insights into the relationships between resource interdependence, power interactions, green supply chain collaboration and performance under TPPI-induced environmental uncertainty. This work investigates an FCEP "bidirectional green supply chain" that contains the forward and reverse distribution channels associated with an FCEP producer-retailer channel dyad. We argue that under TPPI, managing such a bidirectional green supply chain relationship becomes more complicated and challenging due to the resulting bidirectional power restructuring in a channel dyad. Furthermore, this work accounts for the constructs of resource interdependence and power asymmetry that characterize the potential responses of FCEP dyadic members to TPPI. Therefore, this work seeks the optimal form for a sustainable and collaborative green supply chain relationship, not merely for a reverse channel relationship. Then, this work investigates the resulting effect on the collaborative relationship and performance of an FCEP producer-retailer bidirectional green supply chain. Specifically, this work enhances green supply chain 
management from the collaborative perspective of resource dependence theory and addresses issues ranging from the spontaneous resource interdependence of chain members to TPPI-induced resource interdependence. To our best knowledge, this work is one of the first empirical studies linking TPPI with channel power restructuring and collaborative relationships in green supply chain management.

The remainder of this paper is organized as follows. Section 2 provides an overview of the main constructs investigated in this work. Section 3 presents the proposed conceptual model that characterizes the causal relationships among the proposed constructs by hypotheses postulated in this work. Section 4 describes the analytical process, including instrument development and methods used for data collection and testing the validity of the proposed model. Analytical results and important findings are discussed in Section 5, followed by concluding remarks and managerial implications in Section 6. Finally, research limitations and suggestions for future research are presented in Section 7.

\section{Overview of Main Constructions}

The main constructs in this work are classified into four domains: (1) TPPI; (2) channel power restructuring; (3) collaborative relationships; and, (4) green supply chain performance. An overview of the main constructs in these four domains is as follows.

\subsection{Third-Party Power Intervention}

This work defines TPPI as the strategic intervention of any powerful social or political organization (termed the third party in this work) to alleviate goal conflicts between business operations and environmental protection. As claimed in research of power theory, power is defined as the ability to influence and control goals, decisions, and behavior of people and organizations either coercively or non-coercively [22,42-45]. In this work, two primary power sources underlying TPPI are considered: (1) political power which is characterized by government intervention via either regulatory or economic measures [46,47]; and (2) social power which is characterized by challenges posed by non-profit organizations (e.g., Greenpeace International and local green organizations) [48-50]. These two types of TPPI-driven power are treated as exogenous variables to the producer-retailer green supply chain in this work.

The political power phenomena of governments manipulating either regulatory or economic instruments to push producers to bear responsibility for greening their products, including used-product collection, recycling, and repairing are ubiquitous worldwide [51]. Well-known examples include the EU WEEE directive, and Restriction on Hazardous Substances (ROHs). For example, to manage end-of-life electrical and electronic products in EU producers are obligated to collect their WEEE products from customers for recovery, recycling and reuse [52,53]. End-customers can leave end-of-life products with Electrical and Electronic Equipment (EEE) retailers when they buy new products [54]. Under two pending Minnesota bills (HF 882 and SF 838), electronics manufacturers are responsible for collection and disposal costs [55]. Moreover, economic instruments, e.g., subsidies, advance recycling fees and penalties for regulatory non-compliance are extensively utilized by governments to urge enterprises and customers to go green. In the UK, a number of green taxes and charges, such as the Renewables Obligation and Landfill Tax, are imposed on businesses to reduce 
environmental impacts [56]. Other similar cases are deposit-refund schemes in Korea and Canada, advance recycling fees levied in Switzerland and Sweden, and advance disposal fees in Japan [57].

In addition to political power emanated from governmental intervention, social power originated from challenges from green organizations are a primary source of TPPI in this work. For example, Greenpeace International, the best-known international environmental organization, publishes its Guide to Greener Electronics quarterly, and has developed green criteria that pressure international electronics companies to improve their corporate energy and climate policies and practices [58]. When targeted companies fail to keep moving toward improvements in their green policies and practices, waste penalty points are deducted from overall scores, such that a firm's rank is, and brand image can be, adversely affected. A germane example is the case of Apple caving into Greenpeace in 2007. Greenpeace repeatedly ranked Apple near the bottom in its green electronics quarterly reports [59]. Although this case was concluded by Apple's apologies and a new green policy, researchers have arguably agreed that under green organization intervention, the economic (e.g., sales and profits) and non-economic (e.g., brand image and reputation) performance of a producer can be seriously affected when it lacks green partnerships for support.

Accordingly, this work characterizes political and social power from an ontological rather than an epistemological perspective in conformity with Bourgeois [29] in delineating objective environments of organizations. Specifically, this work treats political and social power caused by the interventions of governments and green organizations as the sources of uncertainties of the task environments of green supply chains. To reduce environmental uncertainty caused by TPPI, a producer must collaborate with its green supply chain partners to move jointly toward the goal of extended producer responsibility. Moreover, TPPI is treated as an exogenous variable in this work, and thus, the strategic feedback of green supply chain members to political actions, such as lobbying and contributions to political campaigns [60,61], which create task environments that are favorable and controllable to green supply chains, are not considered in this study's scope.

\subsection{Channel Power Restructuring}

This work investigates the power restructuring of FCEP producer-retailer green supply chains under TPPI from a resource dependence perspective, and thus, aims at two related inter-organizational behavioral phenomena, (1) interdependence; and (2) power asymmetry.

The issue of interdependence, in reality, has garnered considerable attention in the field of resource dependence theory. It exists ubiquitously in inter-organizational behavior, particularly when one organization cannot fully control all the conditions required for completing an action or gaining the desired outcome from an action [30]. Generally, the concept of interdependence originates in social exchange theory and is used to explicate the interest-induced power interaction between two entities (e.g., organizations or persons) [14,48,62]. It is fully utilized in resource dependence theory to rationalize how organizations depend on each other to achieve desired outcomes under environmental uncertainties [15,30].

In Thompson [14], three types of task interdependence, pooled, sequential, and reciprocal, characterize three types of coordination: standardization; planning and scheduling; and mutual adjustment between organizations. These are used by Crook and Combs [15] to investigate sources of 
bargaining power in supply chains. Conversely, Preffer and Salanick [30] characterized interdependence as outcome interdependence and behavioral interdependence, both of which may occur alone or together in the process of inter-organizational power interactions. Outcome interdependence occurs when the outcome achieved by an organization is dependent on another organization. For example, consider an FCEP producer-retailer distribution channel, where the producer (e.g., Apple) may possess channel power sources, such as legitimate power, expert power, and referent power, as it dominates market demand with its brand image, reputation, and unique product attributes and production technology. As resource dependence theory characterizes resources as a set of power, the aforementioned channel power sources can then be regarded as unique resources of the producer. Relative to the producer, the contracted retailer (e.g., Apple's franchisees) may possess information power as it may own valuable information regarding consumer preferences, attitudes, and intentions. In this case, outcome interdependence (e.g., channel performance measured by sales, profits, and product inventory levels) exists in the channel dyad. To respond quickly to consumer needs, dyadic members (i.e., producers and contracted retailers) must cooperate and coordinate in logistics activities (e.g., inventory control, packaging, distribution, and transportation), and thus, behavioral interdependence exists in the channel dyad.

Although interdependence is indispensible when organizations seek external resources from other organizations to increase their viability, organizations are likely to take actions to reduce their dependence on the resources of others, thereby altering the distribution of channel power, which is typically interpreted as the relative ability to control the resources required in channel dyads $[63,64]$. For instance, El-Ansary et al. [63] claimed that channel power is the ability of one channel member (e.g., the producer) to control the goals and decision variables of another member (e.g., the retailer) in a channel dyad. Therein, organizations lacking essential resources will seek to develop inter-firm relationships with those who have the needed resources, and, thus, are defined as target members with less power than that of source members in channel dyads [64-66]. Similarly, resource dependence theory claims that ability to control resources can be characterized in such different forms as resource possession, access to resources, and ability to make rules or regulate the use of resources [30]. Correspondingly, channel power can be viewed as a strategic source of influence that comes from the relative ability of an organization to control the resources required to reduce task uncertainty in channel dyads.

Accordingly, power asymmetry is ubiquitous in inter-organizational interactions, leading to a power imbalance, which remains a critical issue in channel relationship management [67]). From a resource dependence perspective, channel power is the source of an organization's relative ability in a channel dyad to control the required resources [68]. Thus, subsequent power asymmetry and its impact on inter-organizational behavior have received tremendous attention in literature [62,67,69-71]. Power asymmetry, which is also called dependence asymmetry, is characterized by the difference between an organization's dependence on its partner and the partner's dependence on that organization [72]. Kumar et al. [67], however, used the term "interdependence asymmetry" to characterize the difference between dependence levels in a channel dyad. Power asymmetry can be measured by the target member's relative dependence on the source member [73], or the source member's power relative to that of the target member [69,70] in a channel dyad. Specifically, Emerson [62] used the term "power advantage" to represent power asymmetry in a channel dyad, where the degree of power advantage of a dyadic member reflects the degree of the other member's excess dependence. 
Additionally, resource dependence theory links the issues of power asymmetry with contingencies and environmental uncertainties, and assumes that power asymmetry is a resource-dependent asymmetrical phenomenon that arises from the effect of environmental uncertainty on the distribution of power to control required resources. Particularly, the source of the most critical environmental uncertainty determines power in either intra-organizations or inter-organizations [30,68]. For example, Preffer and Salanick [30] applied a conceptual model to interpret how an organization's structure and actions change via changes in the distribution of power and control within an organization that are caused by the effects of organizational environments relative to the source of uncertainty, constraints, and contingency. Extended from Preffer and Salanick [30], we infer that channel power asymmetry arises from the difference in relative ability of dyadic members to handle environmental uncertainties and contingencies.

\subsection{Collaborative Relationship}

Despite the fact that power asymmetry may contribute to a variety of effects on channel climate and performance [34,37,74-76], the resulting channel relationships are not necessarily adverse to channel dyads. Instead, a growing number of relationship marketing scholars favor the idea that organizational interdependence is rooted in harmonic, symbiotic, and collaborative relationships for sustainable business operations [35-39]. Specifically, a long-term and stable inter-organizational collaborative relationship can reduce transaction cost [77], improve risks sharing under task environmental uncertainties [78,79], and increase competitive advantage and economic performance [80-84].

Collaborative relationships are rooted in collaborative advantage, which can maximize the joint benefits of a group of autonomous organizations that work strategically by sharing goals, complementary resources (including knowledge) and capabilities [85,86]. As such, a collaborative relationship results from collaborative partners' relational rents to gain joint benefits [87], which cannot be created independently by any isolated organization [88]. Moreover, the benefits shared by collaborative organizations must be greater than the benefits gained by working alone. As noted in the work by Cao and Zhang [84], collaborative advantage can stimulate collaborative partners to strive collectively for joint value creation, as characterized by the positive-sum game in a rent-seeking process. Conversely, resource dependence theory asserts that collaborative relationships are a relational means of developing cooperative and coordinating linkages in a negotiated environment to manage the interdependence of organizations [30]. Moreover, collaborative relationships help collaborative firms access complementary resources [79]. Collaborative relationships can be achieved via different mechanisms, such as trade associations, cartels, coordinating councils, joint venture, reciprocal trade agreements, and norms [89,90], each representing a form of power sharing at different levels that stabilize and coordinate mutual interdependence.

As prerequisites and features of collaborative relationships fit cases of inter-organizational vertical collaboration (e.g., green supply chain collaboration), this work embeds the construct of collaborative relationship in the proposed conceptual model to investigate the induced mediating effect on the performance of producer-retailer green supply chains under TPPI. Motivated by the work of Cao and Zhang [84], this work treats collaborative relationship as a meta-construct, containing the key elements of joint action and relationship quality, to characterize the collaborative relationship in a green supply 
chain in the process and relational domains, respectively. Therein, joint action can be regarded as inter-organizational collaborative behavior in terms of business goals and processes $[71,91,92]$. According to Zaheer and Venkatraman [91], joint action reflects a move toward a close relationship involving dyadic members fulfilling focal activities cooperatively, where a high degree of joint action reflects a high degree of cooperation and collaboration, thereby leading to stable and long-term relationships between dyadic members. By contrast, the elements of relationship quality in this work are used to characterize the relational focus, such as mutual trust and commitment, of a collaborative relationship. In reality, relationship quality has been utilized widely to reflect the overall character of an exchange relationship in early studies of channel relationship management $[67,93,94]$. For instance, Kumar et al. [67] characterized relationship quality using such dimensions as conflict, trust, commitment, willingness to invest in a relationship, and expectation of continuity. Skarmeas et al. [94] conceptualized relationship quality using several key constructs, i.e., trust, commitment, and satisfaction. Accordingly, this work also asserts that the construct of collaborative relationship is in the relational quality domain.

\subsection{Green Supply Chain Performance}

This work treats green supply chain performance as a construct used to reflect the achievement of joint goals of the collaborative green supply chain members under TPPI. Although there is plenty of literature investigating enterprise performance of green supply chain practices, most published works aim the performance measures at an organizational level [95-99] rather than an inter-organizational level. In Zhu and Sarkis [97], the relationships between green supply chain practices and a firm's performance are examined from economic and environmental perspectives. One distinctive feature of their performance measures is that not only positive (e.g., decreased waste treatment costs) but also negative (e.g., increased costs in green investment) economic performance measures are considered to characterize the effects of green supply practices on a firm's economic performance. Similarly, aiming at the automotive industry Azevedo et al. [99] investigated the influence of green practices on green supply chain performance, where they assessed green supply chain performance in three aspects: economic, operational and environmental performance domains, from a firm's perspective.

Extended from the previous literature in assessing green supply chain performance, this work characterizes the construct of green supply chain performance in the aspects of economic, operational, and environmental performance of the FCEP producer-retailer bi-directional green supply chains under TPPI. Additionally, this work incorporates the notion of "customer green value adding" into the proposed framework to improve its characterization of FCEP green supply chain performance in green value creation. In reality, the notion of customer green value adding stems from the concept of psychological benefits which has been increasingly used in the fields of psychological economics, applied psychology, and related applications to rationalize the changes in human cognition, emotion, and physiology that contribute to additional positive values toward an object (e.g., products and services) [100]. It also encompasses a person's perceptions and expectations with respect to valued outcomes toward an object or activity, where psychological processes play a mediating role $[101,102]$. For instance, consumers may experience the intrinsic warm glow feeling of well-being as a result of the moral satisfaction attributed to purchasing eco-friendly products [103,104]. Motivated by these 
early studies, we, thus, introduce the notion of consumer green value adding into the proposed model in aid of characterizing FCEP green supply chain performance.

\section{Model and Hypotheses}

Building upon advances in the green supply chain management and resource dependence theory literature, this work investigates the issue of FCEP producer-retailer green supply chain collaboration under TPPI from a resource dependence perspective. As mentioned, TPPI differs worldwide, and the resulting effects of political and social power on channel power restructuring, collaborative relationship management and green supply chain performance must be identified. From a producer's point of view, extending the existing producer-retailer distribution channels into bi-directional green supply chains to serve end-customers can be more efficient and effective than outsourcing to logistics companies for implementing extended producer responsibility. Particularly, in considering accessibility to end-customers, we assert that an FCEP producer may rely markedly on the resources of a contracted retailer (e.g., favorable store locations and human resources) to fulfill not only forward logistics/marketing but reverse logistics activities as used-product repairing and recycling under TPPI. Nevertheless, some literature [105] has noted that third-party (e.g., governments) intervention via regulatory and financial instruments may increase the reverse logistics partners' bargaining power when negotiating with producers before achieving cooperative contracts. We conjecture that such a power-shift phenomenon may stem from the changes in inter-organizational resource dependence situations revealed in FCEP green supply chains under the influence of political and social power. This argument may hold particularly when a producer relies heavily on a contracted retailer's resources to facilitate green product marketing as well as reverse logistics service such as used-produced repairing and end-of-life product collection to carry extended producer responsibility.

To characterize the power interplay and collaborative relationship between an FCEP producer and its contracted retailer as they move toward a collaborative green supply chain under the influence of political and social powers in the TPPI context, this work proposes a conceptual framework (Figure 1). Specifically, we investigate whether TPPI-driven political and social power has significant effects on the interdependence and power structure of FCEP producer-retailer channel dyads, and subsequently influences their collaborative relationship and channel performance. Therein, we argue that an FCEP green supply chain's sustainable competitive advantage relies on a sustainable collaborative relationship and superior green supply chain performance, including consumer green value adding. Therefore, the correlations among four primary domains, (1) TPPI-driven political and social power; (2) channel power restructuring; (3) collaborative relationship; and (4) green supply chain performance, are codified in the proposed conceptual framework.

Six hypotheses and their theoretical underpinnings are proposed below. For clarity, the producer and contracted retailer are referred to as the source member and target member, respectively. 
Figure 1. Proposed conceptual framework.

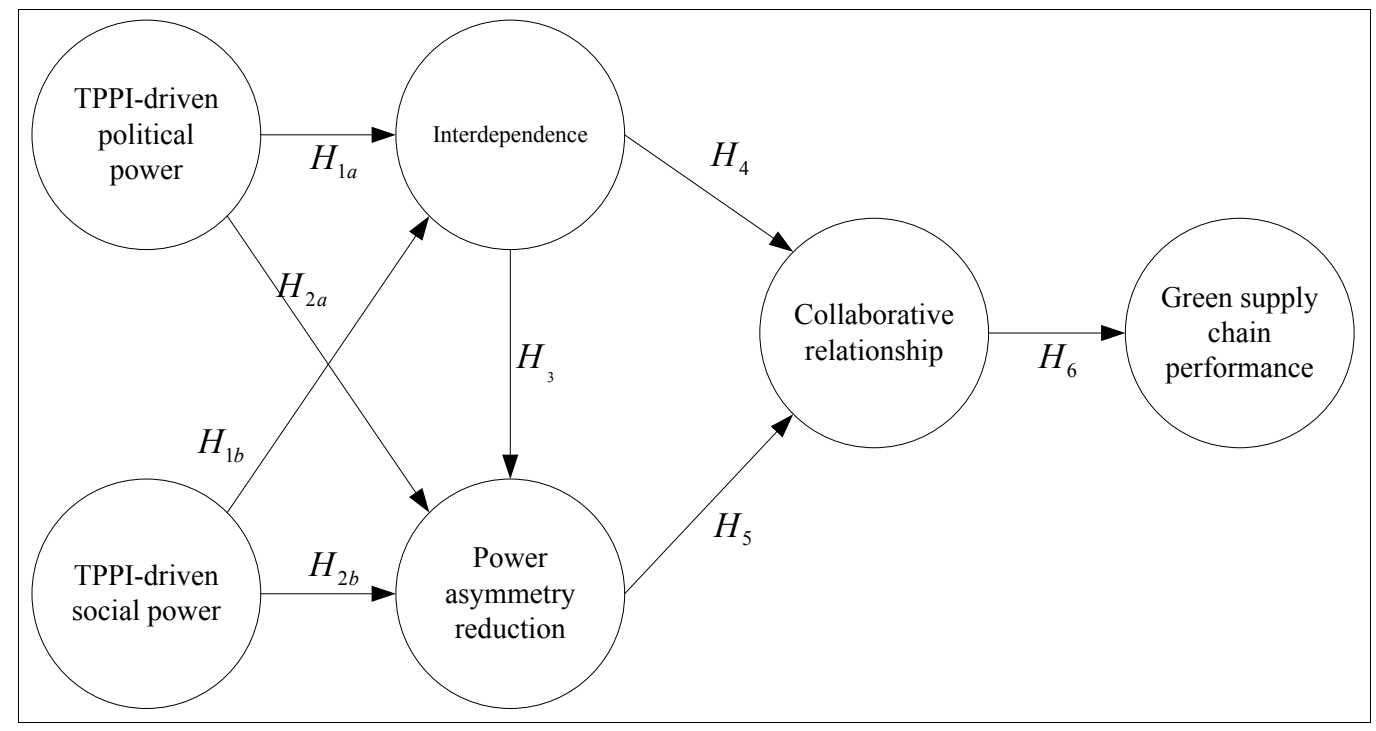

\subsection{TPPI-Driven Political and Social Powers vs. Interdependence}

Observed from green supply chain practices under TPPI, an FCEP producer and its contracted retailer likely work together closely and collectively to gain long-term joint competitive advantage and for extended producer responsibility from a resource dependence perspective. In reality, serious e-waste problems worldwide and the resulting take-back laws that make producers bear most responsibility for collecting and recycling e-wastes have become a global issue in efficient e-waste management [13]. According to resource dependence theory [30], political and social powers oriented from a larger socio-political system have increased the uncertainties of task environments of the producer-retailer channel dyad in an FCEP green supply chain [40,41]. Despite the fact that WEEE directives identify producers as the entity that must bear most extended producer responsibility, numerous EU states have involved retailers in take-back systems to bear jointly the responsibility of e-waste collection with producers. Collection at retail outlets is the primary measure facilitating end-of-life product returns from end-customers [106]. Similar phenomena exist in Asia (e.g., Japan, South Korea, and Taiwan), where retailers play the key role of e-waste collectors, even though producers bear the major responsibility of e-waste collection and recycling [107]. In Japan, FCEP branders favor establishing their own reverse channels with contracted retailers to facilitate end-of-life product returns from end-customers, controlling recycled-material input quality for green manufacturing, and optimizing recyclability by greener designs [12]. As a supply chain partner of an FCEP producer, the contracted retailer is likely to bear extended producer responsibility with the producer coercively and non-coercively under the influence of governments and green organizations, respectively $[11,108]$. When the FCEP producer fails to comply with green regulations (e.g., take-back laws and RoHS), the contracted retailer's economic performance (e.g., sales and profits) will be influenced, particularly when the producer is the retailer's key supplier [9,16].

Furthermore, we argue that TPPI-driven political and social power likely increases the mutual dependence of the FCEP producer and contracted retailer in the forward channel. For instance, to comply with RoHS or green criteria issued by Greenpeace, an FCEP producer is likely to invest, 
coercively or non-coercively, in green production technology and eco-friendly materials/components to achieve green production $[59,109]$. Such green investment increases the FCEP producer's channel power as expert power [48], thus increasing the contracted retailer's dependence on the producer's research and development (R\&D) resources to improve economic performance (e.g., sales and profits). Nevertheless, the success of green marketing seems to rely on the contracted retailer's resources (e.g., sales points and salesmen's capabilities) and cooperative efforts [110]. In reality, evidence from numerous practical cases have indicated that producers rely heavily on the resources and cooperation of contracted retailers to introduce and promote the green features of products (e.g., hybrid vehicles and power-efficient home appliances) in forward distribution channels [111,112]. Such an inference holds particularly true when the producer adopts the green differentiation strategy as a competitive strategy that highlights the green features and eco-benefits of green products to gain competitive advantage in green markets.

Accordingly, we assert that under TPPI-driven political and social power, an FCEP producer and its contracted retailer increasingly rely on each other in a bi-directional green supply chain to reduce the uncertainty of task environments. Thus, we postulate the following hypotheses.

Hypothesis 1a. TPPI-driven political power has a positive effect on the interdependence between a producer and its contracted retailer in an FCEP bi-directional green supply chain.

Hypothesis 1b. TPPI-driven social power has a positive effect on the interdependence between a producer and its contracted retailer in an FCEP bi-directional green supply chain.

\subsection{TPPI-Driven Political and Social Power vs. Power Asymmetry Reduction}

Despite the ubiquity of power asymmetry in inter-organizational power interplays, including that in green supply chains, this work is concerned with how the FCEP producer-retailer members' power is restructured under TPPI. Drawn from resource dependence theory, we argue that political and social power in the larger socio-political system push an FCEP producer and its contracted retailer to seek balanced power under TPPI. In this work, a power balance is defined as a symmetric mutual dependence condition in which no players, neither FCEP producers nor contracted retailers, have the power advantage needed to control unique resources under TPPI. According to resource dependence theory, TPPI via direct (e.g., regulatory instruments) or indirect (e.g., green organizations claims) measures increases the uncertainty of external environments of FCEP green supply chains [18,30]. Therein, neither producers nor retailers can be isolated from the lifespan of an FCEP [11]. Instead, FCEP producers and retailers are more likely to work together in the form of reciprocal resource interdependence to reduce TPPI-induced environmental uncertainties jointly encountered by dyadic members. Consequently, dyadic members may have two sources of organizational and environmental uncertainties under TPPI: one is the diversity and volatility of green laws and policies (e.g., take-back directives and RoHS) imposed by governments; and the other is social norms and challenges typically raised by green organizations $[29,113,114]$. These environmental uncertainties under TPPI contribute to operational and relational risks commonly faced by all producers and retailers in FCEP green supply chains [115,116]. Particularly, relational risks generally arise from the possible defection of the reverse channel partner, and not fulfilling a commitment or tasks to comply with green laws and directives [117,118]. To alleviate these uncertainties under TPPI, both the producer and contracted 
retailer will likely seek closer cooperation rather than leveraging power advantage to gain short-term benefits exploited from the partner under reciprocal task interdependence [15,62]. Accordingly, we argue that TPPI may stimulate the willingness of dyadic members to seek a power-balanced cooperative relationship in an FCEP producer-retailer bi-directional green supply chain; thus, the following hypotheses are postulated.

Hypothesis 2a. TPPI-driven political power has a positive effect on alleviating the power asymmetry between a producer and its contracted retailer in an FCEP bi-directional green supply chain.

Hypothesis 2b. TPPI-driven social power has a positive effect on alleviating power asymmetry between a producer and its contracted retailer in an FCEP bi-directional green supply chain.

\subsection{Interdependence vs. Power Asymmetry Reduction}

As noted by Preffer and Salanick [30], inter-organizational interdependence is characterized as either outcome or behavioral interdependence, implying that dyadic members must rely on the resources and actions of each other to achieve mutually dependent business goals. Therein, neither dyadic member can fully control all the resources required for completing an action or gaining the desired outcome from an action. Such an argument particularly holds true in the study case - the FCEP producer-retailer bi-directional green supply chains under TPPI - as the FCEP producer and contracted retailer might be best off working together in the form of reciprocal interdependence to reduce the uncertainty of external environments under TPPI [14,15]. As resource dependence theory views resources as a set of power, the channel power of dyadic members (either a producer or retailer) under TPPI is rather minor compared to the political and social power of the larger socio-political system. Thus, we argue that no dyadic member can reduce TPPI-based environmental uncertainty without the help of dyadic partners, even when they possess dominant channel power such as the expert and referent power of an FCEP producer and the informational power of a contracted retailer [48,119]. Through reciprocal interdependence, the dyadic producer-retailer members are, thus, unlikely to leverage their power advantage, including bargaining power, to covet short-term benefits squeezed from their partners under TPPI [15]. Instead, they tend to seek power-balanced equilibrium in response to the increased uncertainty of task environments under TPPI. Accordingly, we propose the following hypothesis.

Hypothesis 3. TPPI-induced interdependence reduces power asymmetry between a producer and its contracted retailer in an FCEP bi-directional green supply chain.

\subsection{Interdependence vs. Collaborative Relationship}

Motivated by Thompson [14], and Crook and Combs [15], this work posits that the interdependence between a producer and its contracted retailer in an FCEP green supply chain likely exists as reciprocal task interdependence under TPPI. As noted in Crook and Combs [15], supply chain members' tasks under reciprocal interdependence are highly dependent on how their partners perform, and, thus, coordination must be achieved by active mutual adjustment via such measures as sharing information, knowledge, and discussion to jointly resolve problems and conflicts [120]. Thus, we argue that, under the increased uncertainty of task environments under TPPI, cooperation and coordination of dyadic 
members (i.e., a producer and contracted retailer) likely extends from a typical distribution channel to an FCEP bi-directional green supply chain for joint extended producer responsibility. As the concept of product stewardship emerges, increasing consensus exists in that the FCEP supply chain partners of producers, including retailers, must be involved and regulated by green laws and social norms $[108,121]$.

Consequently, such TPPI-induced reciprocal task interdependence may facilitate the dyadic collaborative behavior of members in either the process or relational domains; that is, increased interdependence promotes the structural and attitudinal convergence of dyadic members in strategic goals and cooperative activities $[122,123]$. Therein, joint actions taken for joint planning and joint problem solving characterize the collaborative behavior of dyadic members from the process perspective [71,91,92]. For instance, an FCEP producer and its contracted retailer may collectively plan green marketing and promotion programs to jointly create consumer values and profits in a forward distribution channel [110,124,125], and moreover, jointly identify problems and work out solutions for compliance with take-back laws [125,126]. Conversely, mutual trust and relationship commitment characterize the dyadic members' collaboration from the relational perspective $[93,94,127]$. Therein, we argue that reciprocal interdependence likely fosters the collaboration between dyadic members that is characterized in the relational domain because reciprocal interdependence reflects the willingness of dyadic members to bear a short-term sacrifice to maintain a stable and cooperative relationship [128], and pursue common interests, mutual understanding, and reciprocity [129]. The increase in reciprocal interdependence increases friendliness and reduces the number of disagreements, conflicts, and the degree of opportunistic behavior in a channel dyad [130]. Therefore, we propose the following hypothesis.

Hypothesis 4. TPPI-induced interdependence strengthens the collaborative relationship between a producer and its contracted retailer in an FCEP bi-directional green supply chain.

\subsection{Reduction in Power Asymmetry vs. Collaborative Relationship}

As noted, the TPPI-driven political and social power likely coercively and non-coercively pushes an FCEP producer and its contracted retailer to move toward a power-balanced equilibrium for joint extended producer responsibility. From a resource dependence perspective, no dyadic member has the power advantage to control alone the critical resources required in a green supply chain, and ability to address solely the issue of TPPI-induced environmental uncertainty [30,40]. Moreover, no dyadic member can be isolated from the lifespan of an FCEP without sharing the responsibility of managing the lifecycle of the product [11]. Such a TPPI-induced process that seeks balanced power in an FCEP producer-retailer green supply chain is rooted in reciprocal resource interdependence [14]. This interdependence pushes dyadic members to collaborate synergistically to respond collectively to the larger political and social power. Therein, we argue that a source member (e.g., an FCEP producer) is likely to refrain from the use of coercive power, including bargaining power, to resolve channel conflicts in a process of seeking balanced power [44,131]. Furthermore, the mutual trust and commitment of dyadic members can be improved under power symmetry [67]. Accordingly, a reduction in power asymmetry by TPPI likely causes dyadic members to collaborate closely to respond jointly to the increased uncertainty of task environments under TPPI [15,84]. 
Furthermore, a source member (e.g., an FCEP producer) will likely adopt relational governance mechanisms to enhance the cooperative relationship of dyadic members, including mutual trust and commitment, as channel power is restructured toward a power-balanced equilibrium under TPPI [71,91,92]. From a source member perspective, relational risks always exist in a channel dyad. This is true particularly when dyadic members perceive that power asymmetry is reduced, where the source member's dependence on the target member's resources increases and task uncertainty increases [132]. The development of mutual trust via relational governance mechanisms is thus an alternative to resolve relational risks that may exist between dyadic members under task uncertainty. According to Zaheer and Venkatraman [91], a source member's effort in relational governance reflects its willingness to move toward a close relationship involving dyadic members fulfilling focal activities cooperatively. For instance, a producer may reciprocally provide technical support and training for the retailer's personnel to enhance the retailer's competence for sales of new/green products, and jointly solve problems encountered in an FCEP green supply chain [94]. Such an idiosyncratic relational governance measure, thus, may further enhance the contracted retailer's trust and commitment to a long-term collaborative relationship with the producer [81]. Therefore, a source member (e.g., an FCEP producer) is likely to adopt relational governance measures to mitigate relational risks when dyadic power asymmetry is reduced under the increased uncertainty of TPPI-induced task environments [71,92].

Accordingly, we propose the following hypothesis to characterize the relationship between power asymmetry reduction and a collaborative relationship in the green supply chain.

Hypothesis 5. Power asymmetry reduction enhances the collaborative relationship between a producer and its contracted retailer in an FCEP bi-directional green supply chain under TPPI.

\subsection{Collaborative Relationship vs. Green Supply Chain Performance}

The inter-organizational collaborative relationship and its effects on supply chain performance have been investigated by numerous studies [84,115], and proved to be positively correlated [25,77,92,133-137]. As claimed in Kalwani and Narayandas [77], maintaining a long-term partnership with consumer firms facilitates s supplier to increase not only short-term benefits (e.g., sales and profits) but also long-term benefits (e.g., market share and competitive advantage). Empirical results from Nyaga et al. [92] demonstrated that trust and commitment do have positive effects positive on performance in a supply chain collaborative context. Moreover, some supply chain management scholars have provided evidence showing that collaborative relationships help improve operational performance (e.g., reduced inventory, fill rate, stockout frequency, and lead time) [138-140] and financial performance [34,84,141-143]. Based on survey data collected from U.S. producers, Cao and Zhang [84] showed that, via the mediating effect of collaborative advantage, supply chain collaboration does deliver benefits, including superior financial performance, to all partners in a collaborative supply chain. Stemming from the collaborative perspective of resource dependence theory, Hofer et al. [34], for example, analytically demonstrated that, via a collaborative relationship, an organization can benefit from the channel partner's dominant market power and obtain improved financial performance.

Extended from the above literature in supply chain performance, we further argue that a closely collaborative channel relationship is favorable for green supply chain performance, particularly in 
terms of environmental performance (e.g., e-waste management and resources usage) and customer green value creation. From a resource dependence perspective [30], inter-organizational collaboration facilitates the establishment of a negotiated task environment that enhances inter-organizational links in goal setting, problem solving, and resource sharing. Through close collaboration, dyadic members (i.e., a producer and its contracted retailer) can easily identify the unique resources required, critical problems to solve, and common norms to follow to manage environmental uncertainty efficiently in the socio-political system, including actors of governments and consumers under TPPI [14,144]. Particularly, a closely collaborative relationship underlying a cooperative producer-retailer green supply chain likely facilitates fulfilling not only joint (green) marketing strategies but also reverse logistics services provided for end-customers through joint planning and actions, thus enhancing green brand image, green value adding, and customer satisfaction in green.

As the above theoretical and practical evidence indicates that as the collaborative relationship increases in closeness, the superiority of channel performance increases for the dyadic producer-retailer green supply chain under TPPI, we postulate the following hypothesis.

Hypothesis 6. The closeness of the collaborative relationship improves joint performance between a producer and its contracted retailer in an FCEP bi-directional green supply chain under TPPI.

\section{Method}

To test hypotheses, this work conducts an empirical study using survey data via confirmatory factor analysis with the analytical method of a structural equations modeling tool (e.g., LISREL). The development of survey instruments for the questionnaire design and survey data collection was carried out via four primary steps: (1) construct operationalization; (2) assessment of content validity; (3) pretests; and (4) sampling and survey data analysis. The primary procedures in instrument development are described as follows.

\subsection{Construct Operationalization}

For construct operationalization, this work performed an extensive literature review to generate a list of potential manifest variables that characterize each latent variable. The associated measurement items for measuring manifest variables were then generated. Typically, construct operationalization is the initial step in assessing content validity and ensuring that measurement items cover the content domain of each construct [145]. Latent variables that refer to the main constructs are identified to characterize causal relationships among key elements in a conceptual model. Theoretically, these latent variables are not directly measurable; however, they can be characterized by multiple manifest variables that can be quantified by survey data. Accordingly, this work defines four categories of latent variables: (1) TPPI; (2) channel power restructuring; (3) collaborative relationship; and, (4) green supply chain performance. Notably, TPPI is further classified into TPPI-driven political power and TPPI-driven social power, as mentioned in Section 2. Channel power restructuring encompasses the constructs of interdependence and power asymmetry reduction. Each of these constructs is associated with a given set of corresponding manifest variables. The rationales of construct operationalization are as follows. 


\subsubsection{Third-Party Power Intervention}

Third-party power intervention has two latent variables, (1) TPPI-driven political power, and (2) TPPI-driven social power, which are oriented from the interventions of governments and green organizations [29,46,47,49,114]. Drawing from literature, the TPPI-driven political power construct is measured by two manifest variables: (1) regulatory instruments [53,57,146], and (2) economic instruments [55,56]. Conversely, the TPPI-driven social power construct is characterized by two manifest variables, direct (e.g., green protests and demonstrations) and indirect actions (e.g., periodic monitoring and assessment of an enterprise's green performance by green organizations), to reflect the influence of social power on green supply chain management in the TPPI context $[58,147,148]$.

\section{Channel Power Restructuring}

In the channel power restructuring category, this work uses two latent variables, (1) interdependence and (2) power asymmetry reduction, to characterize the power interplay in a green supply chain under TPPI. Both constructs, interdependence and power asymmetry reduction, correlate with the dyadic members' dependence [30]. For operationalization of these two constructs, the dependence needs of dyadic members are measured first. To be consistent with prior research, this work measured the dependence of dyadic members using three manifest variables: (1) dependence in terms of resources and exchange outcome [30,119]; (2) availability of alternative partners [67,72,149]; and (3) channel-specific investments [71,128,150]. The last two manifest variables reflect the degree of replaceability and induced switching cost in the case of partner replacement. Particularly, a certain number of works measure inter-organizational dependence based on the dyadic member's perception of its own and its partner's replaceability in a channel dyad [67,70-72,126,149]. Drawing from the work by Kumar et al. [67] and Gulati and Sytch [71], interdependence was characterized by averaging the dependence scores of dyadic members (i.e., summing the dependence scores of dyadic members divided by 2). The above measurement standardization measure ensures that "interdependence" was measured on a scale consistent with those of other latent variables in this work. Power asymmetry was characterized by the absolute value of the difference between dependence scores of the dyadic members. Then, the magnitude of power asymmetry reduction used in this work was identified by taking the upper bound of the measurement scale minus the power asymmetry value calculated above, where the upper bound value of the measurement scale is 7, as a 7-point Likert-type scale was used in this work.

\subsubsection{Collaborative Relationship}

For the construct of collaborative relationship, this work uses key elements of joint action and relational quality to characterize the collaborative relationship of an FCEP green supply chain, following supply chain collaboration literature [36,77,84]. Based on claims made by Heide and Miner [125] and Claro et al. [151], we argue that the manifest variables of joint action reflect the dyadic members' effort for collaboration in the FCEP green supply chain. Therefore, this work adopts joint planning $[124,125]$ and joint problem solving $[84,126]$ as two manifest variables. In the relational quality domain, this work adopts mutual trust $[67,93,96]$ and mutual relationship commitment $[94,130]$ 
as two manifest variables that characterize the relational quality of dyadic member collaboration under TPPI.

\subsubsection{Green Supply Chain Performance}

In this work, green supply chain performance is measured in (1) economic [97,112], (2) operational [152,153]; (3) environmental performance [97,153]; and (4) customer green value adding [100,103], based on green supply chain management and consumer psychology literature (Section 2). Therefore, the corresponding four manifest variables were utilized to characterize FCEP green supply chain performance under TPPI. Differing from early studies focused on organization-level performance assessment [25,95-97], this work focuses on the inter-organization level. Specifically, this work investigates the perception of target members about the extent to which the green supply chain performance is influenced by TPPI-driven political and social power through the mediating effects of reduced power asymmetry and enhanced collaborative relationship.

\subsection{Assessment of Content Validity}

This work designed measurement items as questionnaire content to measure manifest variables, where each manifest variable was associated with at least two measurement items. In total, 64 measurement items were proposed at this stage by extensively reviewing literature and consulting academic and industrial experts. Measurement items for a scale cover the content domain of a manifest variable [145,154]. Of the potential 64 measurement items, 14 items were designed for TPPI-driven political power and social power, 18 items for channel power restructuring, 15 items for collaborative relationship, and 17 items for green supply chain performance. For each measurement item, a 7-point Likert-type scale was used to indicate the extent to which survey respondents agree or disagree with each statement, where 1 represented "strongly disagree and 7 represented "strongly agree".

Then, this work assessed content validity to ensure that designed measurement items can measure what they intend to measure. Assessment of content validity is subjective, relying on the expert judgments of the extent to which the content of each measurement item is valid [155]. Following the literature [155-157], this work adopted the method of logical validity to assess content validity. First, this work applied the assessment tool suggested in Rubio et al. [155] to measure the representativeness of each measurement item on a 4-point scale, where 1 and 4 indicate that the item is "not representative" and is "highly representative", respectively. Next, five content experts were invited to form an expert panel. A content expert refers to person who has published important research or considerable experience in related areas [157]. The expert panel was asked to determine whether an item matches the associated manifest variable. They then rated each item in terms of representativeness and clarity on the 4-point scale.

Following Rubio et al. [155], this work adopted three indices: interrater agreement (IRA); content validity index (CVI); and factorial validity index (FVI). These indices assessed the content validity of the instruments. The IRA index was used to determine how well the experts agree with each other based on their ratings of a given measurement item with the criterion of either representativeness or clarity. Among the selected 64 measurement items, 60 items had IRA indices $>0.8$, which is the threshold recommended by Rubio et al. [155] for assessment with criterion of representativeness or 
clarity, indicating that overall interrater reliability is strong. By contrast, the CVI was calculated only to assess the degree to which content experts agreed in defining measurement items as representative of a relatively homogeneous collection. Thus, this work calculated a CVI value for each item. The resulting item-based CVI values were in the range of $0.50-1.00$. The average CVI value was 0.85 , which is also greater than 0.8 , indicating that instrument content validity is good [155]. Finally, this work calculated the FVI values to measure the extent to which measurement items matched the associated manifest variables based on the content experts' judgments. Each item had its own FVI value, which was determined by the number of experts who agreed that the item belonged to the associated manifest variable divided by the total number of experts in the expert panel. The average FVI value across all items was 0.93 , which is greater than 0.8 , indicating that the measurement items are highly acceptable.

Through the above analysis, we conclude that the content validity of instruments is acceptable. Furthermore, this work removed measurement items with a CVI value lower than 0.8 to enhance the content validity of the instruments, complying with the measure suggested by Davis [158]. In total, 55 measurement items were used to measure manifest variables in this work.

\subsection{Pretests}

Interviews were then conducted with 18 key decision makers, including top managers, procurement, logistics, and marketing sector directors, at retailers of FCEPs as pretests of the questionnaire. Interviewees were asked to check whether an item's wording is appropriate; items were reworded when necessary. Our rationale in selecting this setting is explicated later. Another pretest was conducted involving another 12 managers of FCEP retailers to finalize the survey instruments. Table 1 summarizes the finalized instruments and citations.

Table 1. Instruments and citations.

\begin{tabular}{|c|c|c|}
\hline \multicolumn{3}{|c|}{ Category 1: Third-party strategic intervention } \\
\hline Latent variables & Manifest variables/measurement items & Citations \\
\hline \multirow{2}{*}{$\begin{array}{l}\text { 1.1. TPPI-driven } \\
\text { political power } \\
\text { (PP) }\end{array}$} & $\begin{array}{l}\text { PP1: Regulatory instruments } \\
\text { (1) Our government adopts green policies and regulations that urge our firm } \\
\text { and contracted brander to bear extended producer responsibility; } \\
\text { (2) International green laws/regulations push our firm and contracted brander } \\
\text { to collectively seek for solutions for green supply chain management and } \\
\text { green marketing; } \\
\text { (3) Our government provide regulatory incentives that urge our firm and } \\
\text { contracted brander to fulfill extended producer responsibility }\end{array}$ & {$[53,57,146]$} \\
\hline & $\begin{array}{l}\text { PP2: Economic instruments } \\
\text { (1) Our government provides financial incentives (e.g., green subsidies) } \\
\text { that urge our firm and contracted brander to fulfill extended producer } \\
\text { responsibility; } \\
\text { (2) Our government adopts economic instruments (e.g., advance recycling fees } \\
\text { and penalties for regulatory non-compliance) that urge our firm and contracted } \\
\text { brander to seek for solutions for reverse logistics }\end{array}$ & {$[55,56]$} \\
\hline
\end{tabular}


Table 1. Cont.

\begin{tabular}{|c|c|c|}
\hline \multicolumn{3}{|c|}{ Category 1: Third-party strategic intervention } \\
\hline Latent variables & Manifest variables/measurement items & Citations \\
\hline \multirow{2}{*}{$\begin{array}{l}\text { 1.2. TPPI-driven } \\
\text { social power (SP) }\end{array}$} & $\begin{array}{l}\text { SP1: Direct intervention actions } \\
\text { (1) Green community's requests about green issues urge our firm and } \\
\text { contracted brander to bear extended producer responsibility; } \\
\text { (2) Green community's demonstrations urge our firm and contracted brander to } \\
\text { bear extended producer responsibility; } \\
\text { (3) Green community's legal pleas about green issues urge our firm and } \\
\text { contracted brander to bear extended producer responsibility }\end{array}$ & \multirow[b]{2}{*}[58,147,148]{} \\
\hline & $\begin{array}{l}\text { SP2: Indirect intervention actions } \\
\text { (1) Green organizations' environmental assessment reports } \\
\text { (e.g., Guide to Greener Electronics) urge our firm and contracted to } \\
\text { bear extended producer responsibility; } \\
\text { (2) Green organizations' assessment measures and criteria urge our firm and } \\
\text { contracted brander to bear extended producer responsibility; } \\
\text { (3) Green organizations' claims via multimedia urge our firm and contracted } \\
\text { brander to bear extended producer responsibility }\end{array}$ & \\
\hline \multicolumn{3}{|c|}{ Category 2: Power restructuring } \\
\hline Latent variables & Manifest variables/measurement items & Citations \\
\hline \multirow{3}{*}{$\begin{array}{l}\text { 2.1. PD: Producer } \\
\text { dependence }\end{array}$} & $\begin{array}{l}\text { PD1: Brander's dependence in resources and exchange outcome } \\
\text { (1) The contracted brander relies greatly on our firm's resources } \\
\text { (e.g., facilities and servers) in a bi-directional green supply chain; } \\
\text { (2) The contracted brander relies greatly on our firm's cooperative effort } \\
\text { in a bi-directional green supply chain; } \\
\text { (3) Termination of the cooperative agreement with our firm will } \\
\text { seriously affect the contracted brander's performance in a bi-directional } \\
\text { green supply chain }\end{array}$ & {$[30,119]$} \\
\hline & $\begin{array}{l}\text { PD2: Availability of alternative partners } \\
\text { (1) There are not enough potential retailers that have comparable resources } \\
\text { (e.g., size, number, and location of sales/service outlets) to meet the contracted } \\
\text { brander's requirements; } \\
\text { (2) There are not enough potential retailers that have comparable performance } \\
\text { to meet the contracted brander's goals; } \\
\text { (3) It would be difficult for the contracted brander to replace the sales and } \\
\text { profits generated by the partnership with our firm }\end{array}$ & {$[67,72,149]$} \\
\hline & $\begin{array}{l}\text { PD3: Channel-specific investments } \\
\text { (1) The contracted brander has made significant relationship-specific } \\
\text { investments tailored for the needs of the green supply chain; } \\
\text { (2) The contracted brander has made significant transaction-specific } \\
\text { investments tailored for the needs of the green supply chain }\end{array}$ & {$[71,128,150]$} \\
\hline $\begin{array}{l}\text { 2.2. RD: Retailer } \\
\text { dependence }\end{array}$ & $\begin{array}{l}\text { RD1: Retailer's dependence in resources and exchange outcome } \\
\text { (1) Our firm relies greatly on the contracted brander's resources } \\
\text { (e.g., franchise, economic incentives, knowledge and technical support) } \\
\text { in a bi-directional green supply chain; }\end{array}$ & {$[30,119]$} \\
\hline
\end{tabular}


Table 1. Cont.

\begin{tabular}{|c|c|c|}
\hline \multicolumn{3}{|c|}{ Category 2: Power restructuring } \\
\hline Latent variables & Manifest variables/measurement items & Citations \\
\hline \multirow{3}{*}{$\begin{array}{l}\text { 2.2. RD: Retailer } \\
\text { dependence }\end{array}$} & $\begin{array}{l}\text { (2) Our firm relies greatly on the contracted brander's brand image and } \\
\text { reputation in a bi-directional green supply chain franchises with multiple } \\
\text { contracted branders; } \\
\text { (3) Termination of the cooperative agreement with our firm will seriously } \\
\text { affect the contracted brander's performance in a bi-directional green } \\
\text { supply chain }\end{array}$ & {$[30,119]$} \\
\hline & $\begin{array}{l}\text { RD2: Availability of alternative partners } \\
\text { (1) There are few potential branders like the contracted brander that can } \\
\text { provide our firm comparable product lines; } \\
\text { (2) There are few potential branders like the contracted brander that have } \\
\text { comparable market power to help our firm to achieve our business goals; } \\
\text { (3) It would be difficult for our firm to replace the sales and profits generated } \\
\text { by the partnership with the contracted brander }\end{array}$ & {$[67,72,149]$} \\
\hline & $\begin{array}{l}\text { RD3: Channel-specific investments } \\
\text { (1) Our firm has made significant relationship-specific investments tailored for } \\
\text { the needs of the green supply chain; } \\
\text { (2) Our firm has made significant transaction-specific investments tailored for } \\
\text { the needs of the green supply chain }\end{array}$ & {$[71,128,150]$} \\
\hline \multicolumn{3}{|c|}{ Category 3: Collaborative relationship } \\
\hline Latent variables & Manifest variables/measurement items & Citations \\
\hline \multirow{3}{*}{$\begin{array}{l}\text { 3. CR: } \\
\text { Collaborative } \\
\text { relationship }\end{array}$} & $\begin{array}{l}\text { CR1: Joint planning } \\
\text { (1) Our firm and the contracted brander plan on joint programs (including } \\
\text { green product promotion, green marketing, and used-product collection); } \\
\text { (2) Our firm and the contracted brander jointly develop demand (including } \\
\text { used-product collection) forecasts; } \\
\text { (3) Our firm and the contracted brander jointly develop long-term collaboration } \\
\text { implementation plans (including extended producer responsibility) }\end{array}$ & {$[124,125]$} \\
\hline & $\begin{array}{l}\text { CR2: Joint problem solving } \\
\text { (1) The contracted brander continuously provides technical supports and } \\
\text { training to our firm; } \\
\text { (2) The contracted brander prioritizes our firm's problems to solve when we } \\
\text { jointly identify problems and work out solutions; } \\
\text { (3) Our firm and the contracted brander shares information and knowledge } \\
\text { with each other when coordinating business processes; } \\
\text { (4) Our firm and the contracted brander jointly identify end-customer needs } \\
\text { (including used-product collection and repairing service) }\end{array}$ & {$[84,126]$} \\
\hline & $\begin{array}{l}\text { CR3: Mutual trust } \\
\text { (1) Our firm and the contracted brander believe that our joint goals (including } \\
\text { extended producer responsibility) can be achieved through the collaboration; } \\
\text { (2) Our firm and the contracted brander are willing to share costs and risks } \\
\text { that can occur in the reverse logistics operations for used-product collection } \\
\text { and repairing }\end{array}$ & {$[67,93,96]$} \\
\hline
\end{tabular}


Table 1. Cont.

\begin{tabular}{|c|c|c|}
\hline \multicolumn{3}{|c|}{ Category 3: Collaborative relationship } \\
\hline Latent variables & Manifest variables/measurement items & Citations \\
\hline \multirow[b]{2}{*}{$\begin{array}{l}\text { 3. CR: } \\
\text { Collaborative } \\
\text { relationship }\end{array}$} & $\begin{array}{l}\text { (3) Our firm believes that the contracted brander will not exploit our resources } \\
\text { to angle for their own interests, and vice verse }\end{array}$ & {$[67,93,96]$} \\
\hline & $\begin{array}{l}\text { CR4: Mutual relationship commitment } \\
\text { (1) Our firm and the contracted brander seek for a sustainable channel } \\
\text { relationship with each other; } \\
\text { (2) Our firm promises to collectively achieve joint goals (including extended } \\
\text { producer responsibility) with the contracted brander, and vice versa; } \\
\text { (3) Our firm is willing to make a short-term sacrifice for the achievement of } \\
\text { joint goals and benefits with the contracted brander if necessary and vice versa }\end{array}$ & {$[94,130]$} \\
\hline \multicolumn{3}{|c|}{ Category 4: Green supply chain performance } \\
\hline Latent variables & Manifest variables/measurement items & Citations \\
\hline \multirow{4}{*}{$\begin{array}{l}\text { 4.GC: Green } \\
\text { supply chain } \\
\text { performance }\end{array}$} & $\begin{array}{l}\text { GC1: Economic performance } \\
\text { (1) Our firm has increasing sales through collaboration with the contracted } \\
\text { brander in a green distribution channel; } \\
\text { (2) Our firm has increasing profits through collaboration with the contracted } \\
\text { brander in a green distribution channel; } \\
\text { (3) Our firm can save operational and investment costs for the contracted } \\
\text { brander when collectively providing used-product collection and repairing } \\
\text { service to customers }\end{array}$ & {$[97,99]$} \\
\hline & $\begin{array}{l}\text { GC2: Operational performance } \\
\text { (1) Our firm and the contracted brander have jointly improved inventory levels } \\
\text { in a green distribution channel; } \\
\text { (2) Our firm and the contracted brander have jointly met on-time delivery } \\
\text { requirements in comparison with industry norms; } \\
\text { (3) Our firm and the contracted brander have jointly met used-product collection } \\
\text { requirements in comparison with industry norms; } \\
\text { (4) Our firm and the contracted brander jointly offers efficient used-product } \\
\text { collection and repairing service to customers in comparison with industry norms }\end{array}$ & {$[152,153]$} \\
\hline & $\begin{array}{l}\text { GC3: Environmental performance } \\
\text { (1) Our firm and the contracted brander have jointly met government's green } \\
\text { regulations in used-product collection and recycling; } \\
\text { (2) Our firm and the contracted brander have helped each other to gain } \\
\text { ISO14000 certificates; } \\
\text { (3) Our firm and the contracted brander achieve the joint goals of electronic } \\
\text { waste management }\end{array}$ & {$[97,153]$} \\
\hline & $\begin{array}{l}\text { GC4: Customer green value adding } \\
\text { (1) Our firm and the contracted brander have jointly enhanced our } \\
\text { green brand images; } \\
\text { (2) Our firm and the contracted brander collectively provide an } \\
\text { eco-friendly purchasing environments to customers; } \\
\text { (3) Our firm and the contracted brander have jointly enhanced customers' } \\
\text { green awareness via joint green advertising and promotion programs; } \\
\text { (4) Our firm and the contracted brander jointly increase our customers' } \\
\text { willingness of returning end-of-life products via our reverse distribution channel }\end{array}$ & {$[100,103]$} \\
\hline
\end{tabular}




\subsection{Sampling and Survey Data Analysis}

Data used for hypothesis tests were collected via an interview questionnaire survey that focused on the FCEP producer-dealer distribution channels in Taiwan for the following reasons. First, as FCEPs have short lifecycles and high brand diversity, the FCEP producer-dealer distribution channels (e.g., producer-wholesaler, producer-retailer, and producer-franchisee channels) are widespread in global markets. An FCEP brand must rely on sophisticated relationship-specific incentives and a dealer's commitment to maintain sustainable competitive advantage in end-customer demand markets. Inter-organizational interdependence and collaboration driven by TPPI determines the survival and competitive advantage of dyadic members in extremely competitive contexts. Second, FCEPs made by Taiwanese high-tech manufacturers, including original equipment manufacturers (OEM), own design manufacturers (ODM), and own-brand manufacturers (OBM), remain dominant in global markets [159]. Leading global FCEP brands, such as Apple, Sony, Hewlett Packard, Dell, and Toshiba, have subcontracted with Taiwanese OEM/ODM firms [160]. Taiwanese FCEP producer-dealer distribution channels are the most complex producer-dealer distribution channels worldwide. Additionally, the dramatic rise in demonstrations by green communities and the government's synchronal adoption of green policies and regulations have push firms, including producers and retailers, to face squarely the joint responsibility for improvements in e-waste collection and recycling in Taiwan [146,161]. Under TPPI, the island-wide scrap-computer collection points mainly consist of computer retailers have been widely allocated to deal with end-of-life FCEP collection and provide consumers with money on the spot for returning end-of-life computers [107]. As the aforementioned TPPI context fits the problem background and focus of this work, using data from Taiwan is suitable.

In this work, measuring the perceptions of contracted retailers of channel power restructuring and collaboration is congruent with the research motivation of TPPI-induced effects on FCEP producer-retailer collaboration when contracted retailers are allocated the additional responsibility of extended producer responsibility jointly with producers. Accordingly, questionnaires were primarily distributed to local retailers in FCEP producer-retailer distribution channels. A sample of 985 FCEP retailers was randomly selected from the members' list of the Taipei Electrical Commercial Association. Taipei Electrical Commercial Association which was founded in 1946 is the most lasting and well-known electrical business association that plays the key role of the professional interface between the government and electrical industries in Taiwan [162]. More recently, Taipei Electrical Commercial Association actively gets allied with several related associations in Chain to not only provide extended business services but also facilitate the two-way communication for electrical companies across Taiwan and China. Several steps were taken to improve the survey's response rate. First, emails were sent and follow-up phone calls were made to sampled retailers to explain the academic purpose of this study, and to urge participation [163]. The corresponding decision makers of sampled retailers were identified as target respondents, including directors and managers of procurement and logistics sectors, and were asked about their willingness to act as survey respondents. A 30-minute face-to-face interview was conducted for each sampled firm when approval was obtained. Furthermore, to ensure response quality, survey respondents were asked to indicate their level of knowledge about their firms' interplays with primary contracted branders, exchange relationships, and performance outcomes on a 7-point Likert-type scale, where 1 indicates "very limited knowledge" and 
7 indicates "very substantial knowledge" [164]. A mean score of 6.11 was obtained, indicating that survey respondents had satisfactory knowledge for this survey.

In total, 297 FCEP retailers filled out the questionnaire. Among these 297 samples, 26 were eliminated for incomplete answers, leaving 271 valid samples $(27.5 \%)$ for analysis. Table 2 presents the sample profile. Roughly 184 (67.9\%) sampled FCEP retail outlets have been operating for more than 5 years, and $52(19.2 \%)$ have been operating for more than 10 years. Over $80 \%$ of retailers had annual sales of FCEPs exceeding US\$500,000. Furthermore, over $80 \%$ of respondents were the top decision makers, including section managers (55.7\%) and company owners (28.1\%), enhancing the credibility of survey data. As most sampled FCEP retailers had multiple franchises for FCEPs, the questionnaire was only for one distribution channel for each dealer linked with its main FCEP producer. All survey respondents were asked in person to respond to questionnaire items on a 7-point Likert-type scale, ranging from 1 for "a very little extent" to 7 for "a very great extent."

Table 2. Sample profile.

\begin{tabular}{lcc}
\hline \multicolumn{1}{c}{ Type of operations } & Number of samples & Ratio (\%) \\
\hline Exclusive dealers & 141 & 52.0 \\
Chain retailers & 118 & 43.5 \\
Producer's/Distributor's own stores & 12 & 4.5 \\
\hline \multicolumn{1}{c}{ Years of channel erection } & Number of samples & Ratio (\%) \\
\hline$<$ 1 year & 28 & 10.3 \\
1 year-5 years & 59 & 21.8 \\
6 years-10 years & 132 & 48.7 \\
$>10$ years & 52 & 19.2 \\
\hline \multicolumn{1}{c}{ Annual sales (US\$) } & Number of samples & Ratio (\%) \\
\hline$<500,000$ & 44 & 16.2 \\
$500,000-1,000,000$ & 68 & 25.1 \\
1,000,000-5,000,000 & 75 & 27.7 \\
$>5,000,000$ & 84 & 31.0 \\
\hline Positions of survey respondents & Number of samples & Ratio (\%) \\
\hline Owners & 76 & 28.1 \\
Section managers & 151 & 55.7 \\
Others & 44 & 16.2 \\
\hline
\end{tabular}

Considering the potential for common method bias caused by using survey data collected from a single respondent per firm, we invited other colleagues of sampled firms to assist survey respondents in the questionnaire survey. In total, $48.1 \%$ of surveys were completed by consensus among multiple personnel who were familiar with managing channel relationships with producers. Furthermore, this work adopted three-stage Harmon's single-factor tests suggested in Podsakoff et al. [165] to ensure that common method bias was not statistically significant when accounting for measurement errors. Test results indicated that nine distinct factors with eigenvalues $>1$ explained $71.3 \%$ of total variance, based on unrotated principal components analysis. Particularly, the first factor accounted merely for $28.6 \%$ of total variance, far below the recommended 50\% threshold [165]. By applying confirmatory factor analysis to Harman's single-factor model [166], the model fit indices, including chi square per degree of freedom $\left(\chi^{2} / d f=13.42\right)$, non-normed fit index $(\mathrm{NNFI}=0.69)$, comparative-fit index $(\mathrm{CFI}=0.73)$, 
root mean square error of approximation $(\mathrm{RMSEA}=0.15)$, were worse than those of the measurement model. In the third stage, two measurement models were considered: one with only traits; and the other one with a method factor as well as traits in the test. Test results revealed that the common method factor merely accounted for $6.9 \%$ of total variance, marginally improving model fit indices. Nevertheless, item loadings of these traits remained significant, despite the involvement by the method factor. Accordingly, common method bias was not a problem.

Moreover, non-response bias was evaluated by comparing early vs. late respondents, and respondents $v s$. non-respondents in terms of their demographic characteristics (i.e., type of operations, years of channel existence, annual sales, and positions of respondents) via $t$-tests based on suggestions by Armstrong and Overton [167]. Test results indicated that no statistically significant differences existed in these two comparison cases at the conventional level of 0.05 , implying that non-response bias is not a problem in this work.

Prior to hypothesis testing, construct validity and reliability of the proposed model were evaluated using confirmatory factor analysis and Cronbach's alpha coefficients, respectively. In adopting the measures suggested by Hair et al. [168], construct validity was examined as (1) convergent validity and (2) discriminant validity. Factor loadings, average variance extracted (AVE) estimates, and composite reliability (CR) estimates associated with manifest variables were used to examine convergent validity of constructs using confirmatory factor analysis. Table 3 lists the results of tests for convergent validity, where all estimated factor loadings exceeded 0.7; the AVE estimate associated with each manifest variable exceeded 0.5 ; and all CR coefficients were greater than the associated AVE estimates, indicating acceptable convergent validity [168]. To assess discriminant validity, this work compared the AVE estimate associated with each latent variable with its shared variance with other constructs (square of correlations between constructs) using the method suggested by Fornell and Larcker [169]. Test results (Table 4) indicate that discriminate validity was good as the AVE estimate associated with each given latent variable was greater than the associated squared correlation between dyadic latent variables [169].

Table 3. Confirmatory factor analysis for convergent validity.

\begin{tabular}{|c|c|c|c|c|c|c|c|c|c|c|}
\hline \multirow{2}{*}{$\begin{array}{c}\text { Latent variable } \\
\text { Manifest variable }\end{array}$} & \multicolumn{2}{|c|}{$\begin{array}{c}\text { TPPI-driven } \\
\text { political power } \\
\text { (PP) }\end{array}$} & \multicolumn{2}{|c|}{$\begin{array}{l}\text { TPPI-driven } \\
\text { social power } \\
\text { (SP) }\end{array}$} & \multicolumn{3}{|c|}{$\begin{array}{c}\text { Producer } \\
\text { dependence (PD) }\end{array}$} & \multicolumn{3}{|c|}{$\begin{array}{c}\text { Retailer dependence } \\
\text { (RD) }\end{array}$} \\
\hline & PP1 & PP2 & SP1 & SP2 & PD1 & PD2 & PD3 & RD1 & RD2 & RD3 \\
\hline Factor loading & 0.83 & 0.81 & 0.70 & 0.72 & 0.76 & 0.82 & 0.73 & 0.75 & 0.88 & 0.73 \\
\hline Standard deviation & 0.12 & 0.14 & 0.15 & 0.16 & 0.13 & 0.11 & 0.12 & 0.14 & 0.10 & 0.12 \\
\hline$t$ value & 5.78 & 7.23 & 6.74 & 5.96 & 6.27 & 5.62 & 5.18 & 6.54 & 7.17 & 5.58 \\
\hline AVE & 0.63 & 0.61 & 0.58 & 0.54 & 0.55 & 0.69 & 0.63 & 0.61 & 0.52 & 0.55 \\
\hline $\mathrm{CR}$ & 0.79 & 0.81 & 0.77 & 0.75 & 0.72 & 0.81 & 0.75 & 0.84 & 0.74 & 0.82 \\
\hline Latent variable & \multicolumn{4}{|c|}{ Interdependence (ID) } & \multicolumn{6}{|c|}{ Power asymmetry reduction (PA) } \\
\hline Manifest variable & ID1 & & ID2 & ID3 & & PA1 & & PA2 & & 43 \\
\hline Factor loading & 0.76 & & 0.83 & 0.73 & & 0.73 & & 0.81 & & 72 \\
\hline Standard deviation & 0.15 & & 0.11 & 0.10 & & 0.13 & & 0.12 & & 11 \\
\hline t value & 5.42 & & 5.87 & 6.04 & & 6.77 & & 8.35 & & 98 \\
\hline AVE & 0.60 & & 0.66 & 0.58 & & 0.62 & & 0.65 & & 53 \\
\hline $\mathrm{CR}$ & 0.79 & & 0.77 & 0.79 & & 0.80 & & 0.76 & & 77 \\
\hline
\end{tabular}


Table 3. Cont.

\begin{tabular}{lllllllll}
\hline \multicolumn{1}{c}{ Latent variable } & \multicolumn{4}{c}{ Collaborative relationship (CR) } & \multicolumn{3}{c}{ Green supply chain performance (GC) } \\
\hline Manifest variable & CR1 & CR2 & CR3 & CR4 & GC1 & GC2 & GC3 & GC4 \\
\hline Factor loading & 0.71 & 0.74 & 0.81 & 0.78 & 0.77 & 0.73 & 0.76 & 0.82 \\
Standard deviation & 0.19 & 0.14 & 0.13 & 0.10 & 0.14 & 0.09 & 0.10 & 0.08 \\
t value & 6.02 & 5.38 & 4.99 & 6.54 & 6.61 & 5.32 & 6.89 & 7.11 \\
AVE & 0.71 & 0.64 & 0.56 & 0.67 & 0.63 & 0.66 & 0.58 & 0.61 \\
CR & 0.83 & 0.77 & 0.81 & 0.79 & 0.77 & 0.74 & 0.79 & 0.82 \\
\hline
\end{tabular}

Significant at $p<0.01$.

Table 4. Analytical result for discriminant validity.

\begin{tabular}{lcccccccc}
\hline \multirow{2}{*}{\multicolumn{1}{c}{ Variable }} & \multicolumn{1}{c}{ Variable correlation } \\
\cline { 2 - 9 } & PP & SP & PD & RD & ID & PA & CR & GC \\
\hline PP (TPPI-driven political power) & 1.00 & & & & & & & \\
SP (TPPI-driven social power) & 0.63 & 1.00 & & & & & & \\
PD (producer dependence) & 0.56 & 0.41 & 1.00 & & & & & \\
RD (retailer dependence) & 0.38 & 0.35 & 0.62 & 1.00 & & & & \\
ID (interdependence) & 0.67 & 0.52 & 0.74 & 0.56 & 1.00 & & & \\
PA (power asymmetry reduction) & 0.43 & 0.39 & 0.56 & 0.31 & 0.62 & 1.00 & & \\
CR (collaborative relationship) & 0.45 & 0.41 & 0.51 & 0.48 & 0.66 & 0.58 & 1.00 & \\
GC (green supply chain performance) & 0.48 & 0.37 & 0.45 & 0.40 & 0.57 & 0.53 & 0.68 & 1.00 \\
\hline Mean & 5.68 & 4.61 & 5.93 & 5.51 & 5.77 & 5.24 & 5.67 & 5.53 \\
Standard deviation & 0.69 & 0.47 & 0.72 & 0.64 & 0.56 & 0.63 & 0.44 & 0.57 \\
AVE & 0.64 & 0.58 & 0.63 & 0.59 & 0.68 & 0.67 & 0.62 & 0.61 \\
\hline
\end{tabular}

Significant at $p<0.01$.

Additionally, each construct was examined using Cronbach's $\alpha$ statistics combined with Squared Multiple Correlation (SMC) indexes generated by LISREL, a well-known software program used for structural equation modeling (SEM) to verify construct reliability. Table 5 presents test results, indicating that all estimated Cronbach's $\alpha$ values were $0.74-0.93$, exceeding the 0.7 cutoff value [170]. The SMC indexes generally exceeded the recommended level of 0.5 [171], implying overall acceptance for construct reliability.

Table 5. Analytical results for construct reliability.

\begin{tabular}{ccccccccccc}
\hline Latent variable & $\begin{array}{c}\text { TPPI-driven } \\
\text { political power } \\
\text { (PP) }\end{array}$ & \multicolumn{2}{c}{$\begin{array}{c}\text { TPPI-driven } \\
\text { social power } \\
\text { (SP) }\end{array}$} & \multicolumn{2}{c}{$\begin{array}{c}\text { Producer } \\
\text { dependence (PD) }\end{array}$} & \multicolumn{3}{c}{$\begin{array}{c}\text { Retailer dependence } \\
\text { (RD) }\end{array}$} \\
\hline Manifest variable & PP1 & PP2 & SP1 & SP2 & PD1 & PD2 & PD3 & RD1 & RD2 & RD3 \\
\hline SMC index & 0.65 & 0.71 & 0.68 & 0.67 & 0.75 & 0.72 & 0.69 & 0.72 & 0.68 & 0.70 \\
Cornbach's $\alpha$ & 0.83 & 0.81 & 0.76 & 0.74 & 0.84 & 0.77 & 0.82 & 0.79 & 0.85 & 0.82 \\
\hline Latent variable & \multicolumn{3}{c}{ Interdependence (ID) } & \multicolumn{3}{c}{ Power asymmetry reduction (PA) } \\
\hline Manifest variable & ID1 & \multicolumn{3}{c}{ ID2 } & ID3 & PA1 & PA2 & PA3 \\
\hline SMC index & 0.81 & 0.77 & 0.65 & 0.73 & 0.83 & 0.87 \\
Cornbach's $\alpha$ & 0.87 & 0.91 & 0.86 & 0.84 & 0.81 & 0.89 \\
\hline
\end{tabular}


Table 5. Cont.

\begin{tabular}{ccccccccc}
\hline Latent variable & \multicolumn{4}{c}{ Collaborative relationship (CR) } & \multicolumn{3}{c}{ Green supply chain performance (GC) } \\
\hline Manifest variable & CR1 & CR2 & CR3 & CR4 & GC1 & GC2 & GC3 & GC4 \\
\hline SMC index & 0.66 & 0.54 & 0.67 & 0.72 & 0.65 & 0.69 & 0.75 & 0.68 \\
Cornbach's $\alpha$ & 0.78 & 0.87 & 0.81 & 0.83 & 0.86 & 0.82 & 0.86 & 0.93 \\
\hline
\end{tabular}

\section{Analysis and Results}

After examining construct reliability and validity, the proposed hypotheses were empirically tested using SEM. The corresponding test results are presented, and discussed as follows.

\subsection{Goodness-of-Fit for the Conceptual Framework}

This work tested hypotheses mainly using maximum likelihood estimation. The goodness-of-fit for the structure of the proposed conceptual framework was examined in advance using the five indexes suggested in the literature [171-173]: (1) normed chi-square (i.e., $\chi^{2} / d f$ ); (2) the goodness-of-fit index (GFI); (3) adjusted GFI (AGFI); (4) root mean square residual (RMR); and (5) standard root mean square residual (SRMR) [171-173]. A normed chi-square value of $<3.0$ indicates a good fit, and $<2.0$ indicates an excellent fit [173]; both GFI and AGFI values $>0.9$ are suggested to ensure a good fit of a structural equation model; and RMR and SRMR values of $<0.05$ indicate good fit of a model [171]. Table 6 presents test results. Overall, the corresponding assessment measures indicate that the proposed conceptual framework has a good fit to collected data, implying that the structure of the proposed conceptual framework is appropriate for characterizing interrelationships among latent variables [172].

Table 6. Goodness-of-fit test results.

\begin{tabular}{lccc}
\hline \multicolumn{1}{c}{ Assessment index } & Estimate & critical value & Indication \\
\hline 1. Normed chi square $\left(\chi^{2} / d f=275.82 / 127\right)$ & 2.17 & $<3.0$ & good fit \\
2. Goodness-of-fit index (GFI) & 0.93 & $>0.90$ & good fit \\
3. Adjusted goodness-of-fit index (AGFI) & 0.92 & $>0.90$ & good fit \\
4. Root mean square residual (RMR) & 0.04 & $<0.05$ & good fit \\
5. Standard root mean square residual (SRMR) & 0.04 & $<0.05$ & good fit \\
\hline
\end{tabular}

\subsection{Influence Analysis of Manifest Variables}

The purpose of the test scenario is to examine the capability of a given manifest variable to characterize its associated latent variable with the influence index $(\lambda)$. Table 7 shows the corresponding numerical results, demonstrating the suitability of all manifest variables for model characterization. Particularly, such manifest variables as "dependence asymmetry alleviation in resources" $\left(\lambda_{P A 1}=0.89\right)$, "joint planning" $\left(\lambda_{C R 1}=0.86\right)$, "mutual trust" $\left(\lambda_{C R 3}=0.85\right)$, and "customer green value creation" ( $\left.\lambda_{G C 4}=0.92\right)$ were significantly suitable for characterizing the corresponding latent variables as their $\lambda$ values exceeded 0.85 [173]. 
Table 7. Estimates of influence indexes $(\lambda)$ for manifest variables.

\begin{tabular}{lll}
\hline \multicolumn{1}{c}{ Latent variables } & Manifest variables & influence indexes $(\lambda)$ \\
\hline \multirow{2}{*}{ PP: TPPI-driven political power } & PP1 & 0.83 \\
\cline { 2 - 3 } & PP2 & 0.81 \\
\hline \multirow{2}{*}{ SP: TPPI-driven social power } & SP1 & 0.75 \\
\hline \multirow{3}{*}{ ID: Interdependence } & SP2 & 0.66 \\
\cline { 2 - 3 } & ID1 & 0.73 \\
\cline { 2 - 3 } & ID2 & 0.77 \\
\cline { 2 - 3 } PA: Power asymmetry reduction & ID3 & 0.84 \\
\cline { 2 - 3 } & PA1 & 0.89 \\
\hline \multirow{3}{*}{ CR: Collaborative relationship } & PA2 & 0.77 \\
\cline { 2 - 3 } & PA3 & 0.83 \\
\cline { 2 - 3 } & CR2 & 0.86 \\
\cline { 2 - 3 } & CR3 & 0.82 \\
\cline { 2 - 3 } GC: Green supply chain performance & CR4 & 0.85 \\
\cline { 2 - 3 } & GC1 & 0.79 \\
\cline { 2 - 3 } & GC2 & 0.75 \\
\cline { 2 - 3 } & GC3 & 0.92 \\
\hline
\end{tabular}

\subsection{Interrelationships among Latent Variables}

In this scenario, this work examined the proposed hypotheses characterized by interrelationships among latent variables. Therein, the interrelationship between a pair of latent variables is characterized by three effects: (1) direct effect; (2) indirect effect; and (3) standardized aggregate effect. The direct effect indicates that a direct causal relationship exists between dyadic latent variables, while an indirect effect indicates that the corresponding relationship is induced by other latent variables as mediators. The standardized aggregate effect is then measured by summing the normalized direct and indirect effects. Table 8 presents analytical results obtained in this scenario. Some managerial insights are provided below.

Table 8. Interrelationships of latent variables.

\begin{tabular}{|c|c|c|c|}
\hline Affected latent variable & \multicolumn{3}{|c|}{ Interdependence (ID) } \\
\hline Influence source & Direct (t-value) & Indirect & Aggregate \\
\hline TPPI-driven political power (PP $\rightarrow$ ID) & $0.56(6.75)$ & & 0.54 \\
\hline \multirow[t]{2}{*}{ TPPI-driven social power $(\mathrm{SP} \rightarrow \mathrm{ID})$} & $0.37(4.48)$ & & 0.36 \\
\hline & \multicolumn{3}{|c|}{ Power asymmetry reduction (PA) } \\
\hline TPPI-driven political power $(\mathrm{PP} \rightarrow \mathrm{PA})$ & $0.63(8.71)$ & \begin{tabular}{|l|l|}
0.40 \\
\end{tabular} & 0.42 \\
\hline TPPI-driven social power $(\mathrm{SP} \rightarrow \mathrm{PA})$ & $0.41(6.79)$ & 0.27 & 0.28 \\
\hline \multirow[t]{2}{*}{ Interdependence $(\mathrm{ID} \rightarrow \mathrm{PA})$} & $0.72(9.25)$ & DDDPDD & 0.30 \\
\hline & \multicolumn{3}{|c|}{ Collaborative relationship (CR) } \\
\hline TPPI-driven political power $(\mathrm{PP} \rightarrow \mathrm{CR})$ & & 1.05 & 0.30 \\
\hline TPPI-driven social power $(\mathrm{SP} \rightarrow \mathrm{CR})$ & & 0.69 & 0.19 \\
\hline Interdependence $(\mathrm{ID} \rightarrow \mathrm{CR})$ & $0.69(7.57)$ & 0.46 & 0.33 \\
\hline
\end{tabular}


Table 8. Cont.

\begin{tabular}{|c|c|c|c|}
\hline Affected latent variable & \multirow{2}{*}{\multicolumn{3}{|c|}{ Interdependence (ID) }} \\
\hline \multirow{2}{*}{ Influence source } & & & \\
\hline & \multicolumn{3}{|c|}{ Collaborative relationship (CR) } \\
\hline \multirow[t]{2}{*}{ Power asymmetry reduction (PA $\rightarrow \mathrm{CR}$ ) } & $0.64(6.81)$ & DIDDDDA & 0.18 \\
\hline & \multicolumn{3}{|c|}{ Green supply chain performance (GC) } \\
\hline TPPI-driven political power $(\mathrm{PP} \rightarrow \mathrm{GC})$ & & 0.61 & 0.23 \\
\hline TPPI-driven social power $(\mathrm{SP} \rightarrow \mathrm{GC})$ & & 0.40 & 0.15 \\
\hline Interdependence $(\mathrm{ID} \rightarrow \mathrm{GC})$ & & 0.67 & 0.26 \\
\hline Power asymmetry reduction $(\mathrm{PA} \rightarrow \mathrm{GC})$ & & 0.37 & 0.14 \\
\hline Collaborative relationship $(\mathrm{CR} \rightarrow \mathrm{GC})$ & $0.58(7.39)$ & 171711 & 0.22 \\
\hline
\end{tabular}

Note: (1) The standardized aggregate effect caused by a source construct is calculated by taking the absolute value of the associated aggregate effect divide by the sum of the absolute values of aggregate effects caused by all the source constructs; (2) The shadow cell is defined as a cell with either an insignificant path coefficient (by t test) or no effect existing in a given path; (3) All paths are significant at 0.01 .

\subsection{TPPI effect on power restructuring}

Test results (Table 8) provide several important findings regarding the effect of TPPI on the restructuring of dyadic member's power in FCEP bi-directional green supply chains. First, t-test results indicate that Hypotheses 1 and 2 hold, as the corresponding estimated t-values (i.e., 6.75, 4.48, 8.71, and 6.79) are significant at 0.01. These results demonstrate that TPPI characterized by either government or a green organization significantly enhance the interdependence and reduce power asymmetry in FCEP producer-retailer bi-directional green supply chains, which is consistent with resource dependence theory [29,30]. From a resource dependence perspective, analytical results add to resource dependence theory with empirical evidence of the influence of political and social power in power restructuring of FCEP producer-retailer green supply chains [40,41]. Particularly, the effect of governmental intervention via regulatory and economic approaches is more significant than that of a green organization by comparing corresponding aggregate effects. Based on this generalization, we argue that TPPI should not be treated as the source of the external environment uncertainties of organizations [27,28]. Instead, extending the collaborative relationship from the inter-organizational level to the larger socio-political system level via measures (e.g., enhancing links with governments and green organizations, building joint goals and objectives, and taking joint actions) can be an important issue in both resource dependence theory and green supply chain management. Specifically, the third party, including governments and non-profit organizations, cannot just be regarded as generators of task uncertainties [29]. Companies should proactively pursue collaborative relationships with third-party members of the larger socio-political system to create sustainable collaborative advantage while moving toward joint goals and benefits.

Furthermore, the resulting close interdependence driven by TPPI further alleviates power asymmetry in FCEP producer-retailer green supply chain dyads. Based on the t-test result (9.25) (Table 8), Hypothesis 3 is accepted, as the direct effect (0.72) of interdependence on power asymmetry reduction is positive and significant, which is consistent with the assertion by Crook and Combs [15]. Particularly, government intervention is likely to stimulate the dyadic members' awareness of the need to enhance resource and task interdependence as the direct effect of TPPI on interdependence is 0.56 
(Table 8), and, unsurprisingly, the resulting indirect effect on power asymmetry reduction is again significant (0.40). Therefore, we conclude that TPPI-induced power restructuring is characterized by the bond of interdependence and power symmetry in FCEP producer-retailer green supply chain for viability and competitive advantage.

\subsection{TPPI effect on collaborative relationship}

Consistent with claims made by Das and Teng [115] and Liu et al. [116], test results (Table 8) indicate that Hypotheses 4 and 5 are accepted as the corresponding t-values (i.e., 7.57 and 6.81) are significant at 0.01 . Therefore, we conclude that the interdependence and power asymmetry reduction in an FCEP producer-retailer green supply chain facilitate the chain members' collaboration under TPPI. Both the interdependence and power asymmetry reduction have significant direct effects $(0.69$ and 0.64 , respectively) on the construct of collaborative relationship, leading to the phenomenon that TPPI by either a government or green organization has a significant indirect effect on the collaborative relationship between dyadic members. Particularly, we infer that the political and social power in the form of TPPI may push producers to increase their effort in joint action to build a long-term cooperative relationship with the contracted retailer in an FCEP green supply chain. Furthermore, governmental intervention via regulatory and economic instruments remains the key influence stimulating the adoption of dyadic members of collaborative measures, as it accounts for $30 \%$ of the standardized aggregate effect, markedly exceeding the value of 0.19 for green organization intervention in the studied case. Additionally, consistent with arguments made by Zaheer and Venkatraman [91] and Dyer and Singh [87], interdependence accounts for the majority (0.33) of the aggregate effect on the dyadic members' collaborative relationship, indicating that the constructs of interdependence and collaborative relationship are strongly correlated. Thus, we conclude that such a collaborative relationship rooted in interdependence and power asymmetry reduction is idiosyncratic, and revealed in the FCEP producer-retailer bi-directional green supply chains under TPPI.

\subsection{TPPI-driven green supply chain performance}

Test results (Table 8) have several important implications for the resulting green supply chain performance through the mediating effects of power restructuring and collaborative relationship under TPPI. First, both TPPI measures, governmental intervention and that by a green organization, have positive indirect effects (i.e., 0.61 and 0.40 , respectively) on green supply chain performance, accounting for a total of 0.38 of the standardized aggregate effect, more than that of the other three constructs - interdependence, power asymmetry reduction, and collaborative relationship. Second, compared the standardized aggregate effect $(0.26)$ of interdependence with those of other constructs, interdependence contributes to the majority of the mediating effect on green supply chain performance under TPPI. This implies that under TPPI, the increase in the dyadic members' interdependence, which leads to an improved collaborative relationship, is key to superior channel performance in FCEP producer-retailer bi-directional green supply chains. Furthermore, the t-test result (7.39) (Table 8) indicates that the construct of collaborative relationship has a positive direct effect $(0.58)$ on green supply chain performance, and, thus, Hypothesis 6 is accepted. This generalization is consistent with the claim made by Cao and Zhang [84] in characterizing the effect of supply chain collaboration on 
collaborative advantage and firm performance, as well as that of Huntley [127] in that supply chain collaboration positively affects buyer-seller relationship quality and economic channel performance.

To present final causal relationships among latent variables, Figure 2 summarizes hypothesis test results, where a circle represents a latent variable, and a rectangle represents a manifest variable. The value associated with a given pair of latent variables represents the corresponding path coefficient, which is consistent with the estimated direct effect (Table 8). All path coefficients in the proposed model are statistically significant, as hypothesized. Overall, analytical results reveal that TPPI induces the dyadic members to move toward a power-balanced condition characterized by interdependence and power asymmetry reduction, thereby enhancing the channel collaborative relationship, which leads to superior green supply chain performance.

Figure 2. The proposed SEM-based hypothetical model.

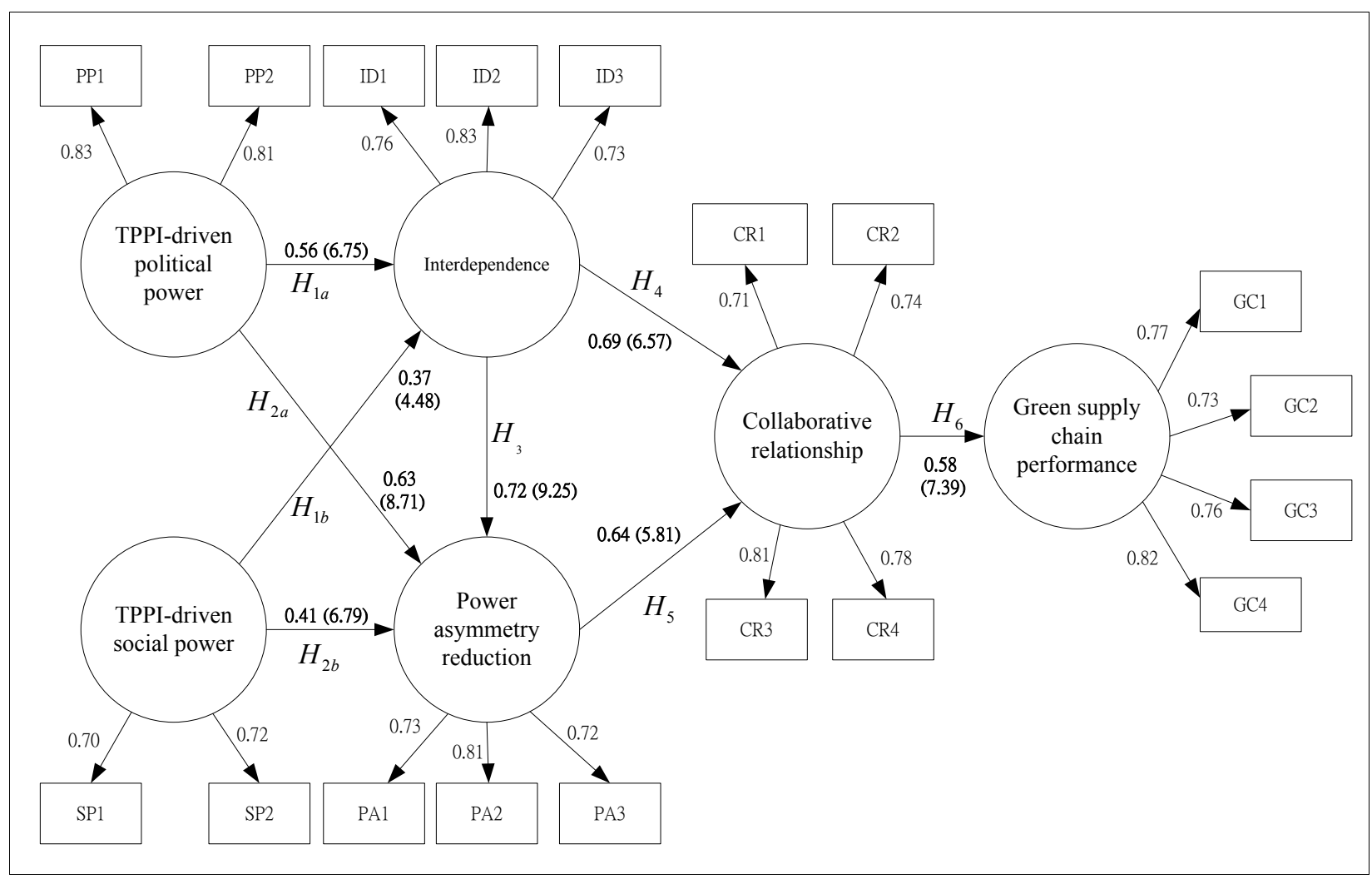

Note: (1) path is significant at 0.01 ; (2) $t$ value is in parentheses; (3) PP1: regulatory instruments; PP2: Economic instruments; SP1: Direct intervention actions; SP2: Indirect intervention actions; ID1: Interdependence in resources and exchange outcome; ID2: Interdependence measured by availability of alternative partners; ID3: Interdependence measured by channel-specific investments; PA1: power asymmetry reduction in resources and exchange outcome; PA2: power asymmetry reduction measured by availability of alternative partners; PA3: power asymmetry reduction measured by channel-specific investment; CR1: joint planning; CR2: joint problem solving; CR3: mutual trust; CR4: mutual relationship commitment; GC1: Economic performance; GC2: Operational performance; GC3: Environmental performance; GC4: Customer green value creation. 


\section{Concluding Remarks and Implications}

This work uses an resource dependence theory-based comprehensive conceptual framework to investigate the interrelationships among channel power restructuring, collaborative relationship, and FCEP green supply chain performance under TPPI. Six hypotheses are given and tested using SEM. A hypothetical model is established to analyze correlations among related constructs in the proposed conceptual framework.

This work adds two unique features to literature on supply chain relationship management. Drawing from resource dependence theory, this work reveals that TPPI generates a high degree of interdependence between an FCEP producer and its contracted retailer in a cooperative extended producer responsibility system when the contracted retailer is allocated additional responsibility in a reverse channel. In this work, TPPI is treated as an influence in the form of social and political power exerted by the socio-political system, which is one major cause of uncertainties of external task environments for green supply chains. Thus, the dyadic producer-retailer members of an FCEP green supply chain must rely not only on a typical vendor-buyer exchange relationship, but also on the reciprocal interdependence underlying a collaborative relationship to reduce external environmental uncertainties under TPPI. Therein, efforts to enhance green supply chain management with resource interdependence and address the issue of extended producer responsibility extended from an organizational perspective to TPPI-driven channel collaboration are implicit in this work. Moreover, this work is one of the first empirical studies linking TPPI with channel power restructuring and collaborative relationship in FCEP green supply chains. To fill this research gap, analytical results indicate that correlations exist among TPPI, inter-organizational interdependence, power asymmetry reduction, collaborative relationship, and green supply chain performance under the influences of political and social power.

Drawing from analytical results, several managerial implications in relation to seeking a channel power-balanced condition and collaborative relationships for superior green supply chain performance under TPPI are summarized as follows.

Based on analytical results, we argue that the characterization of channel power in FCEP green supply chains should not be limited to typical seller-buyer organizational power interplay. Instead, a comprehensive conceptual framework of channel power should account for the influences of political and social power, as the socio-political system has vested interests in FCEP green supply chains. Consequently, we argue that a new channel power structure in green supply chain contexts should contain interdependent power influences from three actors: (1) the source member; (2) the target member; and (3) the socio-political system, including governments, green organizations, and consumers. Additionally, a fourth actor, the market influence of competitors/outside options in a competing green supply chain, should also be considered.

From a source member (e.g., a producer) perspective, political and social power as intervention by the socio-political system undoubtedly exists, and increases task uncertainty in global and green supply chain contexts. Furthermore, such political and social power codified in TPPI is likely to contribute to "push force" to restructure dyadic members' channel power as they move toward power-balanced equilibrium in an FCEP green supply chain. Particularly, governments' regulatory approaches influence task environments in which those actors operate, including business processes (e.g., green 
production, reverse logistics operations, and contracting) and performance (e.g., financial reporting, audits, and security compliance). Therefore, the source member must rely on additional resources from the target member (e.g., contracted retailer) for extended producer responsibility and green marketing programs (e.g., the collaboration between Apple and its global contracted retailers to provide gift cards to end-customers for green marketing and recycling programs). Meanwhile, other competitors (e.g., competing producers) characterized by relative market power also exist and compete with the source member for complementary resources from the target member, resulting in "pull force" that may dilute the interdependence of the incumbent channel dyad (i.e., source and target members) under TPPI. The influence attributed to competitors' relative market power also suggests that a large number of negotiation opportunities exist for the target member (e.g., a contracted retailer). For instance, an FCEP producer must consider a contracted retailer's response in negotiation under the bidding effect of its competitors (i.e., competing producers), which may provide alternatives [174] to the contracted retailer, on the negotiated decision of the contracted retailer.

Conversely, like the target member, a contracted retailer is also likely to perceive the increase in the interdependence and collaborative relationship in an FCEP green supply chain, moving dyadic members toward a power-balanced equilibrium under TPPI (i.e., political and social power). From a sustainable resource dependence perspective, the target member can leverage the power restructuring effect to gain additional benefits from the collaborative advantage jointly created with the source member while moving toward power-balanced equilibrium. Therein, the manager of a contracted retailer can leverage such TPPI (e.g., green regulations and intervention by green organizations) to shift channel power characterized as legitimate and informational power [48] into its firm's favorable resources. For instance, the contracted retailer can request specific investment from the source member, joint brand strategies, joint promotion and advertising programs, and priority in new-product franchises in an FCEP bi-directional green supply chain.

Accordingly, the source member must adopt ambidextrous relational governance mechanisms to alleviate the reverse effects induced by the "push" and "pull" forces for viability and transform them into positive effects for sustainable development under TPPI. We argue that typical resource dependence theory [30] can be further extended to deal with resource dependence and power interplay issues from a "micro-inter-organizational" level to a "macro-inter-organizational" level. Therein, key members (e.g., governments, green organizations, and consumers) of the socio-political system may no longer be treated only as sources of uncertainties in task environments. Instead, treating them as partners, and getting them involved in a larger collaborative green supply chain system to identify joint goals, taking collaborative actions (e.g., sharing information and knowledge), and sharing collaborative advantage are "triple-win" measures noteworthy. In reality, optimal green policy instruments, e.g., take-back and recycling programs, should also get feedbacks from green supply chain members. Additionally, a lot of anecdotal evidence has suggested that governments can also join in collaborative green supply chains in different forms, e.g., buyers of recycled products for public procurements. Figure 3 shows this new power structure relative to the typical channel power structure. The influence of political and social power as TPPI and that of relative market power are involved when characterizing comprehensively the resource interdependence and power interplay between the source and target members under the uncertainty of external environments. 
Figure 3. New channel power structure in green supply chain contexts.

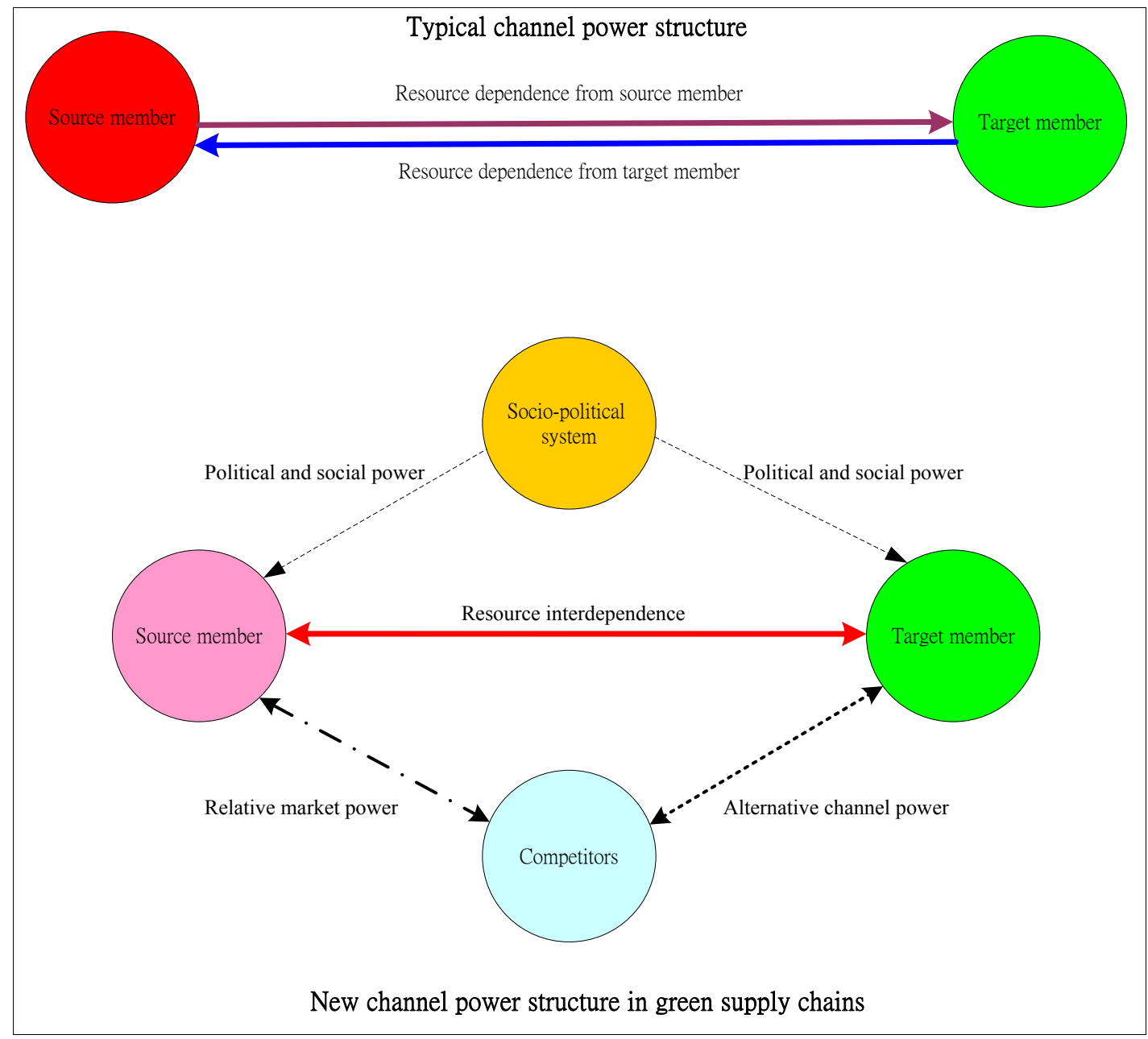

\section{Limitations and Future Research}

Despite the contribution of this work to literature, it has limitations that warrant further investigation. The study scope is limited to two-tier bi-directional distribution channels formed typically by dyadic members (e.g., FCEP producers and contracted retailers). Model extension and tests for various types of power structures, including direct and indirect power interplays with third parties (e.g., governments, green organizations, competitors, and end-customers) may enrich generalizations and managerial insights into resource dependence theory-based supply chain collaboration. The relational governance mechanisms, including the combined use of transactional and relational mechanisms applying for different types of power structures, are also noteworthy. Moreover, other forms of channel relationships, such as producer-reverse logistics supplier and producer-green component supplier channels under the influence of TPPI also warrant additional research. For instance, the cross-country transfer of hazardous waste, particularly in terms of illegal e-waste export, remains as a critical issue in global reverse supply chain management, where the transnational supply collaboration with additional chain partners (e.g., carriers and logistics companies) should be investigated further. Such an issue, however, seems to go beyond the scope of this work, in which a contracted retailer is allocated the responsibility of local collection and repairing in a reverse channel, thereby acting as the interface between end-customers and the producer in this work. In the case of cross-country transfer of e-waste, 
a producer remains the source member, which also acts as a shipper/exporter, whereas the target member can be an international carrier/logistics company. Therefore, a new partnership with a new target member should be defined to address the aforementioned issue. As this work investigates bi-directional channel relationships between FCEP producers and contracted retailers, a survey respondent should ideally be familiar with activities in both forward and reverse distribution channels, and involved in the corresponding decision processes in a sampled firm. Nevertheless, practices of forward and reverse channel activities are typically handled by two different departments, namely, the marketing and logistics departments in a firm. As explicated in Section 4, in addition to survey respondents as key informants, their colleagues working in these two departments were invited to assist them in answering survey questions. However, elaborate sampling and survey methods can be adopted to enhance the validity of data samples.

Future research should collect additional data from various industries or across different countries for comparative analyses to test the validity of the proposed conceptual framework and hypotheses. Further extension of the conceptual model linked with issues of resource dependence theory-based sustainable competitive advantage of a green supply chain for competing and strategic marketing planning may also warrant further investigation. Moreover, the influence of competitor power via the mediating effects of threats and bidding on source and target members is ignored in this work, but is worthy of future research. Power reorientation and relationship quality management for the case of a source member dealing with the strategic alliance of target members in a green supply chain is another interesting issue to address in future research. In addition to trust and commitment, we suggest that other constructs characterizing the dyadic members' attitudes about collaborative advantage sharing and risk sharing as they moves toward sustainable supply chain collaboration are also noteworthy.

In summary, this work systematically characterizes the interrelationships among TPPI, channel power restructuring, collaborative relationship, and FCEP green supply chain performance in a resource dependence theory-based conceptual framework, and demonstrates the applicability of resource dependence theory and channel power theory to practical cases for green supply chain relationship management. More importantly, we claim that creating a chain-based collective regulatory compliance strategy via collaboration across FCEP green supply chain members is urgently needed, and will be the next global issue in global TPPI contexts.

\section{Acknowledgments}

This research is supported by grants NSC 100-2628-H-002-138-MY4 and NSC 102-2410-H-002166-MY3 from the National Science Council of Taiwan. The authors also wish to thank the Guest Editors and referees for their helpful comments and suggestions. Any errors or omissions remain the sole responsibility of the authors.

\section{Conflicts of Interest}

The author declares no conflict of interest. 


\section{References}

1. Bruce, M.; Daly, L.; Towers, N. Lean or agile: A solution of supply chain management in the textiles and clothing industry? Int. J. Oper. Prod. Manag. 2004, 24, 151-170.

2. Barnes, L.; Lea-Greenwood, G. Fast fashioning the supply chain: Shaping the research agenda. J. Fash. Mark. Manag. 2006, 10, 259-271.

3. MacCarthy, B.L.; Jayarathne, P.G.S.A. Fast fashion: Achieving global quick response (GQR) in the internationally dispersed clothing industry. In Innovative Quick Response Programs in Logistics and Supply Chain Management, International Handbooks on Information Systems; Cheng, T.C., Choi, T.-M., Eds.; Springer-Verlag: Berlin, Germany, 2010; pp. 37-60.

4. Turker, D.; Altuntas, C. Sustainable supply chain management in the fast fashion industry: An analysis of corporate reports. Eur. Manag. J. 2014. Available online: http://dx.doi.org/ 10.1016/j.emj.2014.02.001 (accessed on 1 April 2014).

5. Ho, J.; Kretz, C. Green electronics take root. Taipei Times, 20 June 2005.

6. Clean Production Action. Establishing effective extended producer responsibility legislation: A checklist for decision-makers, zero waste advocates and waste managers. Available online: http://www.docstoc.com/docs/90360991/1-Establishing-Effective-Extended-ProducerResponsibility (accessed on 1 April 2014).

7. Stevels, A.; Huisman, J. An industry vision on the implementation of WEEE and RoHS. WEEE-forum, European Association of Electrical and Electronic Waste Take Back Systems. Available online: http://www.weee-forum.org/ (accessed on 1 April 2014).

8. ETC. Electronics Take-Back Coalition. Computer takeback. Available online: http://www.computertakeback.com (accessed on 15 January 2010).

9. Cincom, Cincom Systems. The high costs of non-compliance for manufacturers. White Paper-Cincom in-depth analysis and review. Available online: http://whitepapers. technologyevaluation.com/view_document/6417/the-high-costs-of-noncompliance-formanufacturers.html (accessed on 1 April 2014).

10. Apple Inc. Apple Recycling Programs. Available online: http://www.apple.com/recycling/ (accessed on 1 April 2014).

11. Emmett, S.; Sood, V. Green Supply Chains-An Action Manifesto; TJ International Ltd.: Cornwall, UK, 2010.

12. INFORM, Inc. PC Recycling in Japan. Available online: http://informinc.org/japanpc.pdf (accessed on 1 February 2004).

13. Atasu, A.; van Wassenhove, L.N. An operations perspectives on product take-back legislation for e-waste: Theory, practice, and research needs. Prod. Oper. Res. 2012, 21, 407-422.

14. Thompson, J.D. Organizations in Action; McGraw-Hill: New York, NY, USA, 1967.

15. Crook, T.R.; Combs, J.G. Sources and consequences of bargaining power in supply chains. J. Oper. Manag. 2007, 25, 546-555.

16. Deffree, S. Apple iPhone contains hazardous substances-Greenpeace. Electronics Weekly, 2007. Available online: http://www.edn.com/electronics-news/4316002/Apple-iPhone-contains-hazardoussubstances-Greenpeace-claims (accessed on 16 October 2007). 
17. Sheu, J.-B.; Chou, Y.-H.; Hu, J.-J. An integrated logistics operational model for green supply chain management. Transp. Res. Part E 2005, 41, 287-313.

18. Sarkis, J.; Zhu, Q.; Lai, K.-H. An organizational theoretic review of green supply chain management literature. Int. J. Prod. Econ. 2011, 130, 1-15.

19. Fleischmann, M.; Beullens, P.; Bloemhof-Ruwaad, J.M.; van Wassenhove, L.N. The impact of product recovery on logistics network design. Prod. Oper. Manag. 2001, 10, 156-174.

20. Flowers, A.D.; Linderman, K. Hazardous waste disposal: A waste-fuel blending approach. Prod. Oper. Manag. 2003, 12, 307-319.

21. Savaskan, R.C.; Bhattacharya, S.; van Wassenhove, L.N. Closed-loop supply chain models with product remanufacturing. Manag. Sci. 2004, 50, 239-253.

22. French, M.L.; LaForge, R.L. Closed-loop supply chains in process industries: An empirical study of producer re-use issues. J. Oper. Manag. 2006, 24, 271-286.

23. Min, H.; Ko, H.J. The dynamic design of a reverse logistics network from the perspective of third-party logistics service providers. Int. J. Prod. Econ. 2008, 113, 176-192.

24. Gavronski, I.; Klassen, R.D.; Vachon, S.; do Nascrimento, L.F.M. A resource-based view of green supply management. Transp. Res. Part E 2011, 47, 872-885.

25. Carter, C.R.; Jennings, M.M. Social responsibility and supply chain relationship. Transp. Res. Part E 2002, 38, 37-52.

26. Cheng, J.-H. Inter-organizational relationships and knowledge sharing in green supply chains-Moderating by relational benefits and guanxi. Transp. Res. Part E 2011, 47, 837-849.

27. Dill, W.R. Environment as an influence on managerial autonomy. Adm. Sci. Q. 1958, 2, 409-443.

28. Duncan, R.G. Characteristics of organizational environments and perceived environmental uncertainty. Adm. Sci. Q. 1972, 17, 313-327.

29. Bourgeois, L.J. Strategy and environment: A conceptual integration. Acad. Manag. Rev. 1980, 5, 25-39.

30. Pfeffer, J.; Salancik, G.R. The External Control of Organizations. A Resource Dependency Perspective; Harper and Row: New York, NY, USA, 1978.

31. Ulrich, D.; Barney, J.B. Perspectives in organizations: Resource dependence, efficiency, and population. Acad. Manag. Rev. 1984, 9, 471-481.

32. Medcof, J.W. Resource-based strategy and managerial powers. Strat. Manag. J. 2001, 22, 999-1012.

33. Mottner, S.; Smith, S. Wal-Mart: Supplier performance and market power. J. Bus. Res. 2009, 62, 535-541.

34. Hofer, C.; Jin, H.; Swanson, R.D.; Waller, M.A.; Williams, B.D. The impact of key retail accounts on supplier performance: A collaborative perspective of resource dependency theory. J. Retail. 2012, 88, 412-420.

35. Brown, J.R.; Lusch, R.F.; Nicholson, C.Y. Power and relationship commitment: Their impact on marketing channel member performance. J. Retail. 1995, 71, 363-392.

36. Bowersox, D.J.; Closs, D.J.; Stank, T.P. Ten mega-trends that will revolutionize supply chain logistics. J. Bus. Logist. 2000, 21, 1-15.

37. Hu, T.-L.; Sheu, J.-B. Relationships of channel power, noncoercive influencing strategies, channel climate and solidarity: A case study of the Taiwan PDA industry. Ind. Mark. Manag. 2005, 34, 447-461. 
38. Palmatier, R.W.; Dant, R.P.; Grewal, D.; Evans, K.R. Factors influencing the effectiveness of relationship marketing: A meta-analysis. J. Mark. 2006, 70, 136-153.

39. Koza, K.L.; Dant, R.P. Effects of relationship climate, control mechanism, and communications on conflict resolution behavior and performance outcomes. J. Retail. 2007, 83, 280-296.

40. Hillman, A.J.; Withers, M.C.; Collins, B.J. Resource dependence theory: A review. J. Manag. 2009, 35, 1404-1427.

41. Aharoni, V.; Maimon, Z.; Segev, E. Interrelationships between environmental dependencies: A basis for tradeoffs to increase autonomy. Strat. Manag. J. 1981, 2, 197-208.

42. Wright, M.C. The Power Elite; Oxford University Press: Oxford, UK, 1951.

43. Dahl, R.A. The concept of power. Behav. Sci. 1957, 2, 210-215.

44. Gaski, J.F. The theory of power and conflict in channels of distribution. J. Mark. 1984, 48, 9-29.

45. Haugaard, M. The Constitution of Power: A Theoretical Analysis of Power, Knowledge and Structure; Manchester University Press: Manchester, UK, 1997.

46. Parsons, T. On the concept of political power. Proc. Am. Philos. Soc. 1963, 107, 232-262.

47. Mouffe, C. On the Political; Routledge: New York, NY, USA, 2005.

48. French, J.R.P., Jr.; Raven, B.H. The bases of social power. In Studies in Social Power; Cartwright, D., Ed.; University of Michigan Press: Ann Arbor, MI, USA, 1959; pp. 150-167.

49. Mann, M. The Sources of Social Power: Volume 1, A History of Power from the Beginning to AD 1760; Cambridge University Press: Cambridge, UK, 1986.

50. Mann, M. The Sources of Social Power: Volume 2, The Rise of Classes and Nation-States 1760-1914; Cambridge University Press: Cambridge, UK, 1993.

51. Kahhat, R.; Kim, J.; Xu, M.; Allenby, B.; Willams, E.; Zhang, P. Exploring e-waste management systems in the United States. Resour. Conserv. Recycl. 2008, 32, 955-964.

52. Hischier, R.; Wager, P.; Gauglhofer, J. Does WEEE recycling make sense from an environmental perspective? The environmental impacts of the Swiss take-back and recycling systems for waste electrical and electronic equipment (WEEE). Environ. Impact Assess. Rev. 2005, 25, 525-539.

53. Ongondo, F.O.; Williams, I.D.; Cherrett, T.J. How are WEEE doing? A global review of the management of electrical and electronic wastes. Waste Manag. 2011, 31, 714-730.

54. Gamberini, R.; Gebennini, E.; Manzini, R.; Ziveri, A. On the integration of planning and environmental impact assessment for a WEEE transportation network-A case study. Resour. Conserv. Recycl. 2010, 54, 937-951.

55. Webster, S.; Mitra, S. Competitive strategy in remanufacturing and the impact of take-back laws. J. Oper. Manag. 2007, 25, 1123-1140.

56. Sinclair, M. The burden of green taxes. Working paper of the Taxpayers' Alliance. Available online: http://www.taxpayersalliance.com/ (accessed on 1 April 2014).

57. OECD. Extended Producer Responsibility: A Guidance Manual for Governments. Available online: http://www.oecd-ilibrary.org/environment/extended-producer-responsibility_ 9789264189867-en (accessed on 20 March 2001).

58. Greenpeace International. Guide to Greener Electronics version 16. Available online: http://www.greenpeace.org/ (accessed on 1 April 2014). (In Chinese) 
59. Murray, J. Jobs apologies Apple caves in to Greenpeace pressure. Business Green. Available online: $\mathrm{http}: / / w w w . b u s i n e s s g r e e n . c o m / b g / n e w s / 1804723 /$ jobs-apologises-apple-caves-greenpeace-ressure (accessed on 1 April 2014).

60. Meznar, M.B.; Nigh, D. Buffer or bridge? Environmental and organizational determinants of public affairs activities in American firms. Acad. Manag. J. 1995, 38, 975-996.

61. Mullery, C.B.; Brenner, S.N.; Perrin, N.A. A structural analysis of corporate political activity. Bus. Soc. 1995, 34, 147-171.

62. Emerson, R.M. Power-dependence relations. Am. Sociol. Rev. 1962, 27, 31-41.

63. El-Ansary, A.I.; Stern, L.W. Power measurement in the distribution channel. J. Mark. Res. 1972, 9, 47-52.

64. Gaski, J.F. Interrelations among a channel entity's power sources: Impact of the expertise of reward and coercion on expert, reference, and legitimate power sources. J. Mark. Res. 1986, 23, 62-77.

65. Frazier, G.L. On the measurement of interfirm power in channels of distribution. J. Mark. Res. 1983, 20, 158-166.

66. Frazier, G.L.; Summers, J.D. Perceptions of interfirm power and its use within a franchise channel of distribution. J. Mark. Res. 1986, 23, 169-176.

67. Kumar, N.; Scheer, L.K.; Steenkamp, J.-B.E.M. The effects of perceived interdependence on dealer attitudes. J. Mark. 1995, 32, 348-356.

68. Preffer, J. Power in Organizations; Pitman Publishing Inc.: Marshfield, MA, USA, 1981.

69. Lawler, E.J.; Bacharach, S.B. Comparison of dependence and punitive forms of power. Soc. Forces 1987, 66, 446-462.

70. Frazier, G.L.; Rody, R. The use of influence strategies in interfirm relationships in industrial product channels. J. Mark. 1991, 55, 52-69.

71. Gulati, R.; Sytch, M. Dependence asymmetry and joint dependence in inter-organizational relationships: Effects of embeddedness on a manufacturer's performance in procurement relationships. Adm. Sci. Q. 2007, 52, 32-69.

72. Buchanan, L. Vertical trade relationships: The role of dependence and symmetry in attaining organizational goals. J. Mark. Res. 1992, 29, 65-75.

73. Anderson, J.C.; Narus, J.A. A model of distributor firm and manufacturer firm working relationships. J. Mark. 1990, 54, 42-58.

74. Duffy, R.; Fearne, A.; Hornibrook, S. Measuring distributive and procedural justice: An exploratory investigation of the fairness of retailer-supplier relationships in the UK food industry. Br. Food J. 2003, 105, 682-694.

75. Coleman, J.E.; Mayo, D.T. Relationship marketing strategies for dominant brands. Innov. Mark. 2007, 3, 21-31.

76. Lai, C.-S. The use of influence strategies in interdependent relationship: The moderating role of shared norms and values. Ind. Mark. Manag. 2009, 38, 426-432.

77. Kalwani, M.U.; Narayandas, N. Long-term manufacturer-supplier relation- ships: Do they pay? J. Mark. 1995, 59, 1-15.

78. Kogut, B. Joint ventures: Theoretical and empirical perspectives. Strat. Manag. J. 1988, 9, 319-332. 
79. Park, N.K.; Mezias, J.M.; Song, J. A resource-based view of strategic alliances and firm value in the electronic marketplace. J. Manag. 2004, 30, 7-27.

80. Mentzer, J.T.; Foggin, J.H.; Golicic, S.L. Collaboration: The enablers, impediments, and benefits. Supply Chain Manag. Rev. 2000, 5, 52-58.

81. Handfield, R.B.; Bechtel, C. The role of trust and relationship structure in improving supply chain responsiveness. Ind. Mark. Manag. 2002, 31, 367-382.

82. Johnson, J.J.; Sohi, R.S. The development of interfirm partnering competence: Platforms for learning, learning activities and consequences of learning. J. Bus. Res. 2003, 56, 757-766.

83. Sheu, C.; Yen, H.R.; Chae, D. Determinants of supplier-retailer collaboration: Evidence from an international study. Int. J. Oper. Prod. Manag. 2006, 26, 24-49.

84. Cao, M.; Zhang, Q. Supply chain collaboration: Impact on collaborative advantage and firm performance. J. Oper. Manag. 2011, 29, 163-180.

85. Kanter, R. Collaborative advantage: The art of alliances. Harv. Bus. Rev. 1994, 72, 96-108.

86. Dyer, J.H. Collaborative Advantage: Winning Through Extended Enterprise Supplier Networks; Oxford University Press: New York, NY, USA, 2000.

87. Dyer, J.H.; Singh, H. The relational view: Cooperative strategy and sources of interorganizational competitive advantage. Acad. Manag. Rev. 1998, 23, 660-679.

88. Corsten, D.; Kumar, N. Do suppliers benefit from collaborative relationships with large etailers? An empirical investigation of efficient consumer response adoption. J. Mark. 2005, 69, 80-94.

89. Gouldner, A.W. The norm of reciprocity: A preliminary statement. Am. Sociol. Rev. 1960, 25, 161-178.

90. Preffer, J.; Nowak, P. Joint ventures and interorganizational interdependence. Adm. Sci. Q. 1976, 21, 398-418.

91. Zaheer, A.; Venkatraman, N. Relational governance as an interorganizational strategy: An empirical test of the role of trust in economic exchange. Strat. Manag. J. 1995, 16, 373-392.

92. Nyaga, G.N.; Whipple, J.M.; Lynch, D.F. Examining supply chain relationships: Do buyer and supplier perspectives on collaborative relationships differ? J. Oper. Manag. 2010, 28, 101-114.

93. Dwyer, F.R.; Schurr, P.H.; Oh, S. Developing buyer-seller relationships. J. Mark. 1987, 51, 11-27.

94. Skarmeas, D.; Katsikeas, C.S.; Spyropoulou, S.; Salehi-Sangari, E. Market and supplier characteristics driving distribution relationship quality in international marketing channels of industrial products. Ind. Mark. Manag. 2008, 37, 23-36.

95. Clarkson, M.B.E. A stakeholder framework for analyzing and evaluating corporate social performance. Acad. Manag. Rev. 1995, 20, 92-117.

96. Fynes, B.; Voss, C.; de Burca, S. The impact of supply chain relationship quality on quality performance. Int. J. Prod. Econ. 2005, 96, 339-354.

97. Zhu, Q.; Sarkis, J. Relationships between operational practices and performance among early adopters of green supply chain management practices in Chinese manufacturing enterprises. J. Oper. Manag. 2004, 22, 265-289.

98. Sarkis, J.; Gonzalez-Torre, P.; Adenso-Diaz, B. Stakeholder pressure and the adoption of environmental practices: The mediating effect of training. J. Oper. Manag. 2010, 28, 163-176.

99. Azevedo, S.G.; Carvalho, H.; Machado, C. The influence of green practices on supply chain performance: A case study approach. Transp. Res. Part E 2011, 47, 850-871. 
100. Hartmann, P.; Apaolaza-Ibanez, V. Consumer attitude and purchase intention toward green energy brands: The roles of psychological benefits and environmental concern. J. Bus. Res. 2012, $65,1254-1263$.

101. Ekehammar, B. Test of a psychological cost-benefit for career choice. J. Vocat. Behav. 1977, 10, 245-260.

102. Bringslimark, T.; Hartig, T.; Patil, G. The psychological benefits of indoor plants: A critical review of the experimental literature. J. Environ. Psychol. 2009, 29, 422-433.

103. Kahneman, D.; Knetsch, J.L. Valuing public goods: The purchase of moral satisfaction. J. Environ. Econ. Manag. 1992, 22, 57-70.

104. Nunes, P.A.L.D.; Schokkaert, E. Identifying the warm glow effect in contingent valuation. J. Environ. Econ. Manag. 2003, 45, 231-245.

105. Sheu, J.-B. Bargaining framework for competitive green supply chains under governmental financial intervention. Transp. Res. Part E 2011, 47, 573-592.

106. Khetriwal, D.S.; Kracuchi, P.; Widmer, R. Producer responsibility for e-waste management: Key issues for consideration-Learning from the Swiss experience. J. Environ. Manag. 2009, 90, $153-165$.

107. Lee, C.H.; Chang, S.-L.; Wang, K.-M.; Wen, L.-C. Management of scrap computer recycling in Taiwan. J. Hazard. Mater. 2000, 73, 209-220.

108. Jacobs, B.W.; Subramanian, R. Sharing responsibility for product recovery across the supply chain. Prod. Oper. Manag. 2012, 21, 85-100.

109. Sheu, J.-B.; Chen, Y.J. Impact of government financial intervention on competition among green supply chains. Int. J. Prod. Econ. 2012, 138, 201-213.

110. Stern, L.W.; El-Ansary, A.I. Marketing Channels, 5th ed.; Prentice-Hall: Upper Saddle River, NJ, USA, 1996.

111. Lampe, M.; Gazda, G.M. Green marketing in Europe and the United States; an Evolving business and society interface. Int. Bus. Rev. 1995, 4, 295-312.

112. Zhu, Q.; Sarkis, J.; Cordeiro, J.J.; Lai, K.-H. Firm-level correlates of emergent green supply chain management practices in the Chinese context. Omega 2008, 36, 577-591.

113. Miller, K.D. A framework for integrated risk management in international business. J. Int. Bus. Stud. 1992, 23, 311-331.

114. Fink, R.C.; James, W.; Hatten, K.J. Duration and relational choices: Time based effects of customer performance and environmental uncertainty on relational choice. Ind. Mark. Manag. 2008, 37, 367-379.

115. Das, T.K.; Teng, B.S. A risk perception model of alliance structuring. J. Int. Manag. 2001, 7, $1-29$.

116. Liu, Y.; Li, Y.; Tao, L.; Wang, Y. Relationship stability, trust and relational risk in marketing channels: Evidence from China. Ind. Mark. Manag. 2008, 37, 432-446.

117. Parkhe, A. Messy research, methodological predispositions and theory development in international joint ventures. Acad. Manag. Rev. 1993, 18, 227-268.

118. Delerue, H. Relational risks perceptions in European biotechnology alliances: The effect of contextual factors. Eur. Manag. J. 2004, 22, 546-556. 
119. Raven, B.H.; Kruglanski, A.W. Conflict and power. In The Structure of Conflict; Swingle, P., Ed.; Academic Press: New York, NY, USA, 1970; pp. 69-109.

120. Gulati, R.; Singh, H. The architecture of cooperation: Managing coordination costs and appropriation concerns in strategic alliances. Adm. Sci. Q. 1998, 43, 781-794.

121. Davis, G.A.; Wilt, C.A.; Barkenbus, J.N. Extended product responsibility: A tool for a sustainable economy. Environment 1997, 39, 10-37.

122. Dimaggio, P.J.; Powell, W.W. The iron cage revisited: Institutional isomorphism and collective rationality in organizational fields. Am. Sociol. Rev. 1983, 48, 147-160.

123. Tajfel, H.; Turner, J.C. The social identity theory of intergroup behavior. In The Social Psychology of Intergroup Relationships; Austin, W.G., Ed.; Brooks-Cole: Pacific Grove, CA, USA, 1986.

124. Heide, J.B.; John, G. Alliances in industrial purchasing: The determinants of joint action in buyer-supplier relationships. J. Mark. Res. 1990, 27, 24-36.

125. Heide, J.B.; Miner, A.S. The shadow of the future: Effects of anticipated and frequency of contract on buyer-seller cooperation. Acad. Manag. J. 1992, 35, 265-291.

126. Lusch, R.F.; Brown, J.R. Interdependency, contracting, and relational behavior in market channels. J. Mark. 1996, 60, 19-38.

127. Huntley, J.K. Conceptualization and measurement of relationship quality: Linking relationship quality to actual sales and recommendation intention. Ind. Mark. Manag. 2006, 35, 703-714.

128. Anderson, E.; Weitz, B.A. The use of pledges to build and sustain commitment in distribution channels. J. Mark. Res. 1992, 29, 18-34.

129. Liu, Y.; Li, Y.; Zhang, L. Control mechanisms across a buyer-supplier relationship quality matrix. J. Bus. Res. 2010, 63, 3-12.

130. Jap, S.D.; Manolis, C.; Weitz, B.A. Relationship quality and buyer-seller interactions in channels of distribution. J. Bus. Res. 1999, 46, 303-313.

131. Etgar, M. Channel domination and countervailing power in distribution channel. J. Mark. Res. 1976, 14, 254-262.

132. Mahapatra, S.; Narasimhan, R.; Barbieri, P. Strategic interdependence, governance effectiveness and supplier performance: A dyadic case study investigation and theory development. J. Oper. Manag. 2010, 28, 537-552.

133. Ganesan, S. Determinants of long-term orientation in buyer-seller relationships. J. Mark. 1994, $58,1-19$.

134. Doney, P.M.; Cannon, J.P. An examination of the nature of trust in buyer-seller relationships. J. Mark. 1997, 61, 35-61.

135. Monczka, R.M.; Petersen, K.J.; Handfield, R.B.; Ragatz, G.L. Success factors in strategic supplier alliances: The buying company perspective. Decis. Sci. 1998, 29, 553-577.

136. Cannon, J.P.; Perreault, W.D. Buyer-seller relationships in business markets. J. Mark. Res. 1999, 36, 439-460.

137. Rokkan, A.I.; Heide, J.B.; Wathne, K.H. Specific investments in marketing relationships: Expropriation and bonding effects. J. Mark. Res. 2003, 15, 210-224.

138. Bowersox, D.J.; Closs, D.J. Logistics Management: The Integrated Supply Chain Process; McGraw-Hill: New York, NY, USA, 1996. 
139. Whipple, J.M.; Frankel, R. Strategic alliance success factors. J. Supply Chain Manag. 2000, 36, 21-28.

140. Daugherty, P.J.; Richey, R.G.; Roath, A.S.; Min, S.; Chen, H.; Arndt, A.D.; Genchev, S.E. Is collaboration paying off for firms? Bus. Horiz. 2006, 49, 61-70.

141. Cavinato, J.L. A total cost/value model for supply chain competitiveness. J. Bus. Logist. 1992, 13, 285-301.

142. Wisner, J.D.; Tan, K.C. Supply chain management and its impact on purchasing. J. Supply Chain Manag. 2000, 36, 32-42.

143. Tan, K.C. Supply chain management: Practices, concerns, and performance issues. J. Supply Chain Manag. 2002, 38, 42-53.

144. Parmigiani, A.; Rivera-Santos, M. Clearing a path through the forest; A meta-review of interorganizational relationships. J. Manag. 2011, 37, 1108-1136.

145. Segars, A.H.; Grover, V. Strategic information systems planning success: An investigation of the construct and its measurement. MIS Q. 1998, 22, 139-163.

146. Wen, L.; Lin, C.-S.; Lee, S.-C. Review of recycling performance indicators: A study on collection rate in Taiwan. Waste Manag. 2009, 29, 2248-2256.

147. Blair, H. Building and reinforcing social accountability for improved environmental. Governance 2008, 9, 33-44.

148. Cashmore, M.; Axelsson, A. The mediation of environmental assessment's influence: What role for power? Environ. Impact Assess. Rev. 2013, 39, 5-12.

149. Heide, J.B. Interorganizational governance in marketing channels. J. Mark. 1994, 58, 71-85.

150. Heide, J.B.; John, G. The role of dependence balancing in safeguarding transaction-specific assets in conventional channels. J. Mark. 1988, 52, 20-35.

151. Claro, D.P.; Hagelaar, G.; Omta, O. The determinants of relational governance and performance: How to manage business relationships? Ind. Mark. Manag. 2003, 32, 703-716.

152. Flynn, B.B.; Huo, B.; Zhao, X. The impact of supply chain integration on performance: A contingency and configuration approach. J. Oper. Manag. 2010, 28, 58-71.

153. Olugu, E.U.; Wong, K.Y.; Shaharoun, A.M. Development of key performance measures for the automobile green supply chain. Resour. Conserv. Recycl. 2011, 55, 567-579.

154. Churchill, G.A. A paradigm for developing better measures of marketing constructs. J. Mark. Res. 1979, 16, 64-73.

155. Rubio, D.M.; Berg-Weger, M.; Tebb, S.S.; Lee, E.S.; Ruch, S. Objectifying content validity: Conducting a content validity study in social work research. Soc. Work Res. 2003, 27, 94-104.

156. Lynn, M.R. Determination and quantification of content validity. Nurs. Res. 1986, 35, 382-386.

157. Grant, J.S.; Davis, L. Selection and use of content experts for instrument development. Res. Nurs. Health 1997, 20, 269-274.

158. Davis, L. Instrument review: Getting the most from your panel of experts. Appl. Nurs. Res. 1992, 5, 194-197.

159. Chu, W.-W. Can Taiwan's second movers upgrade via branding? Res. Policy 2009, 38, 1054-1065.

160. Law, K. Relationships with supply chain partners affecting internal operations of high-tech manufacturers in Taiwan. J. High Technol. Manag. Res. 2009, 20, 31-39. 
161. Fan, K.S.; Lin, C.; Chang, T.C. Management and performance of Taiwan's waste recycling fund. J. Air Waste Manag. Assoc. 2005, 55, 574-582.

162. Taipei Electrical Commercial Association. Available online: http://www.teca.org.tw/ (accessed on 24 April 2014).

163. Dillman, D. Mail and Telephone Surveys: The Total Design Method; John Wiley and Sons: New York, NY, USA, 1978.

164. Fowler, F.J. Survey Research Methods; Sage: Newbury Park, CA, USA, 1993.

165. Podsakoff, P.M.; MacKenzie, S.; Lee, J.; Podsakoff, N. Common method biases in behavioral research: A critical review of the literature and recommended remedies. J. Appl. Psychol. 2003, 88, 879-903.

166. Sanchez, J.I.; Brock, P. Outcomes of perceived discrimination among hispanic employees: Is diversity management a luxury or a necessity? Acad. Manag. J. 1996, 39, 704-719.

167. Armstrong, J.S.; Overton, T.S. Estimating nonresponse bias in mailing surveys. J. Mark. Res. 1977, 14, 396-402.

168. Hair, J.; Black, W.; Babin, B.; Anderson, R. Multivariate Data Analysis, 7th ed.; Prentice-Hall Inc.: Upper Saddle River, NJ, USA, 2010.

169. Fornell, C.; Larcker, D.F. Evaluating structural equation models with unobservable variables and measurement errors. J. Mark. Res. 1981, 18, 39-50.

170. Cronbach, L.J. Coefficient alpha and the internal structure of tests. Psychometrika 1951, 16, 297-334.

171. Joreskog, K.G.; Sorbom, D. LISREL 8 and PRELIS 2 for Windows Manual; SSI, Inc.: Chicago, IL, USA, 1993.

172. Anderson, J.C.; Gerbing, D.W. Structural equation modeling in practice: A review and recommended two-step approach. Psychol. Bull. 1988, 103, 411-423.

173. Bagozzi, R.P.; Yi, Y. On the evaluation of structural equation model. Acad. Mark. Sci. 1988, 16, 76-94.

174. Muthoo, A. Bargaining Theory with Applications; Cambridge University Press: Cambridge, UK, 2002.

(C) 2014 by the author; licensee MDPI, Basel, Switzerland. This article is an open access article distributed under the terms and conditions of the Creative Commons Attribution license (http://creativecommons.org/licenses/by/3.0/). 